\title{
Information technologies, embodiment and growth
}

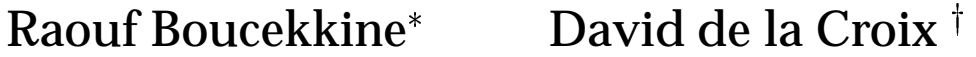

August, 2000

\begin{abstract}
This paper studies the conditions under which an IT revolution may endogenously occur. To this end, we construct an endogenous growth multisectoral model with a preeminent IT sector. Technological progress is embodied: New softwares can only be run on the the most recent generations of hardware. While the new softwares are copyrighted during a fixed period of time, they become public knowledge at a certain point in time, which generates positive externalities in the rest of the economy. First, we find that our model can give rise to multiple steady states due to strategic complementarities. Then we focus on the dynamic response of the economy to adverse shocks on the level of disembodied technological progress. Substitution effects are shown to arise: The labor resources are diverted from the final goods sector to sustain the creation and production of new softwares. During the IT boom, labor productivity's growth slowdowns, the skill premium rises as well as the value of firms undertaking research. However, the registered IT boom is always transitory and nothing can be said about the long run sustainability of an IT-driven growth regime.
\end{abstract}

Keywords: Information technology, Vintage capital, Embodied technological progress, Endogenous growth.

Journal of Economic Literature: E22, E32, O40, C63.

${ }^{*}$ Corresponding author. IRES, Université catholique de Louvain, Place Montesquieu, 3, B-1348 Louvain-la-Neuve, Belgium. E-mail: boucekkine@ires.ucl.ac.be.

†FNRS and IRES, Université catholique de Louvain. E-mail: delacroix@ires.ucl.ac.be 


\section{Introduction}

The sector of information technologies has been recently invoked to crucially matter in the recent trends and performances of national economies (see for example Gordon, 1999, Greenwood and Jovanovic, 1999, Whelan, 2000, and Jorgenson and Stiroh, 2000). There is now a common view according to which we are entering in a "new economy", the age of information technologies (IT hereafter). The huge productivity growth figures registered for the durable goods sector, and in particular for the computer sector (around $42 \%$ per year from 1995 to 1999 following Gordon, 1999), makes it difficult to argue against such a view. However, some issues are still debated and will be debated until a more substantial historical experience is available. The main debated issue concerns the status of this IT age from an historical perspective. Some authors like Greenwood, Yorukoglu or Jovanovic (see Greenwood and Yorukoglu, 1997, and Greenwood and Jovanovic, 1999a) have argued that we are witnessing the Third Industrial Revolution: After an adoption period along which the productivity slowdown takes place due to learning costs and slow diffusion, the IT are now driving the rest of the sectors. The productivity gains should accordingly spread over the economy exactly as the major discoveries affected the pace of economic activity during the nineteenth century's Industrial Revolution.

Robert Gordon $(1999,2000)$ has argued against this strongly optimistic view of the recent recovery of the US economy. While the huge figures for productivity growth in the computer sectors are out of question, thus assigning a particular weight to IT in the recovery of total factor productivity growth in the USA, Gordon observes that no significant spillovers are taking place from IT to the rest of the sectors. Even the productivity slowdown has worsened for the non-durable goods manufacturing sectors over the period 1995-1999 compared with the period 1972-1995. Therefore, according to Gordon, if undeniably something important is changing in the US economy, it is by no way comparable with the major discoveries of the nineteenth century. More doubts can be raised about the validity of comparing IT, and especially Internet, with the great inventions of the past. Interestingly it should be noted that much of the use of Internet involves substitution of existing means. This view is shared by Jorgenson and Stiroh (1999) who interpret the current boom of IT as "a vast and continuing substitution of IT equipment for other forms of capital and labor". This massive substitution is fundamentally due to a relative price effect: As properly shown by Gordon in his 1990's influential book, the relative price of durable goods, including hardware and communication, has considerably decreased since the mid-1970's, and even more sharply in the recent years. The so-called Solow paradox according to which productivity gains due to IT are showing up everywhere except in the statistics, can be therefore solved easily: “...This substitution generates substantial returns for the economic agents who undertake IT investments and restructure their activities in order to increase the role of IT. There is little evidence however that substitution is accompanied by technical change as this term is used by economists".

In a more recent article, Jorgenson and Stiroh (2000) emphasize the methodological and statistical issues underlying the debate. Following Griliches (1994), they observe that many of the goods and services producing high-tech capital may not be adequately 
measured. ${ }^{1}$ Clearly a considerable research effort should be done to appraise and assess the real contribution of IT to growth and productivity so as to conclude more safely about the long run sustainability of the current growth regime. It is not an obvious task at all to measure adequately the effects of Internet on productivity for example. Clearly a highly desirable approach to these measurement problems should account for the two channels through which IT may affect productivity, production effects Vs usage effects: The estimation of productivity gains from the IT revolution should not be confined by construction to the production of hardware and software and other IT means, it should also try to capture the effects of their usage in the other sectors. A brilliant attempt at building up a consistent methodological set-up incorporating the latter aspect is due to Whelan (2000). Although he does not bring out any definitive answer as for the long run sustainability of the current IT-driven growth regime, his contribution is most worthwhile in that it highlights the methodological problems that one should tackle when accounting for the specific outcomes of a very specific sector, the IT sector.

While the methodological issues are far from settled, the theoretical debate about the determinants, implications and the viability of the IT revolution is even more open. This paper is devoted to a theoretical analysis of the view considering the IT boom as the Third Industrial Revolution. As mentioned above, this view interprets the current recovery as an age of maturity of IT after an adoption period along which the productivity slowdown takes place due to learning costs and slow diffusion. A representative contribution of this mainstream literature can be found in Greenwood and Yorukoglu's 1997 paper. The story is based on the concept of embodied technical change: What primarily characterizes the IT revolution is the embodied nature of the resulting technological progress. A recent and fundamental empirical contribution underlying the role of embodiment is due to Greenwood, Hercowitz and Krusell (1997). Although there is still some debate about the exact quantitative implications of embodiment (see for example Hulten, 1992, for a survey), it is now widely admitted that the latter is an unavoidable aspect of modern growth. Since by construction the technological progress conveyed by the IT sector is fundamentally embodied, the so-called "embodied question" is even more crucial regarding this sector.

The fact that after 1974 there has been an acceleration in the rate of embodied technological progress is indeed reflected by the observed acceleration in the rate of decline of the relative price of equipment as reported by Gordon (1990) for example. This is even more striking for IT equipment as emphasize Jorgenson and Stiroh (2000): The price of computer investment fell around $17 \%$ per year from 1990 to 1996 while the price of IT equipment to households fell $24 \%$ annually. Within a computable general equilibrium set-up, Greenwood and Yorukoglu introduce these features by assuming that the rate of embodied technological change has exogenously accelerated suddenly and permanently from 1974. As the pre-exisiting firms are unable to immediately use the new techniques at their full potential, a relatively long adoption period takes place which duration depends upon different endogenous costs (fundamentally skilled labor to facilitate the adoption). Therefore, the story told here does not provide any explanation for the acceleration in the rate of embodied technological progress in the mid-seventies, rather it assumes it. This paper is intended to remedy this shortcoming.

\footnotetext{
${ }^{1}$ Oliner and Sichel (2000) note that the November 1999 NIPA revision weakens Gordon's conclusions.
} 
Using a computable general equilibrium approach, we endogenize embodied technological progress: Instead of assuming an exogenous initial shift in the latter, we study the consequences of an exogenous negative supply shock to basically mimic the first oil shock. We then consider to what extent this exogenous shock can be responsible for an endogenous acceleration of the embodied technical progress. Our approach is consequently much less ad-hoc.

Here comes a short description of our model. First at all it should be noted that our model generates endogenous growth and displays non-monotonic dynamics due to a very specific time structure involved by our patent protection specifications. Particular attention has been paid to the modeling of the IT sector. Indeed, we model this sector to meet the following characteristics. First at all, technological progress is mainly embodied. The new softwares can only be run on the the most recent vintages of hardware for technical compatibility requirements. Secondly, the innovators are rewarded by a market power (copyrights) so as to stimulate innovation and growth. This is a typical specification in research-based growth models. In our model, innovating corresponds to expanding the varieties of available softwares (horizontal differentiation, see Romer, 1987). Finally, while the new softwares are copyrighted during a fixed period of time, they become public knowledge at a certain point in time, which generates positive externalities in the rest of the economy. In this sense, the information technology may a be a powerful engine of growth.

The model is written in discrete time with an infinite time horizon. Two production sectors and one research sector are explicitly modeled. The final good sector uses a vintage capital technology in line with the canonical model of Solow (1960) and employs raw as well as skilled labor. Only the most recent generations of capital (hardware) are compatible with the new varieties of intermediate goods (softwares). The softwares are produced in a second sector, the intermediate goods sector, by the means of a simple linear technology involving a single input, unskilled labor. The producers of patented softwares charge a mark-up while those who produce softwares already in the public domain use marginal-cost pricing. The research sector is designed to expand the varieties of softwares according to a linear technology with a unique input, skilled labor. To model externalities, we assume that the cost of research decreases with the level of public knowledge, which in turn depends on the number of the existing (produced) softwares. Research is financed by households through a perfect financial market. The households behavior is standard. In particular, skilled and unskilled labor supplies are taken inelastic.

After deriving the optimality conditions, we show that the model reduces into a system of eight dynamic (difference) equations. We first study the existence and uniqueness of the steady state growth paths. Due to strategic complementarities, our model can generate multiple steady states. This is a standard result in the literature since the seminal contributions of Cooper and John (1988) and Young (1993). Strategic complementarities arise in our model due to the embodiment hypothesis exactly as in del Río (1999) or in Boucekkine, del Río and Licandro (2000): The demand for the new softwares is intimately linked to the investment decisions, and so is profitability of R\&D. Investment is the unique channel through which technological advances are enforced, and as such it is a central determinant of the return to R\&D. This complementarity between investment and R\&D is responsible for multiplicity to occur. 
Unfortunately the complexity of our steady state system disables any analytical resolution. So we resort to numerical simulations. We also resort to numerical experiments to study the dynamics of our model along the lines outlined above. In particular, we thoroughly analyze how the dynamics of innovation (through the expanding varieties of softwares) interact with the accumulation of physical capital in the growth process. Several other interesting questions are also raised within our computable general equilibrium setting (such as the skill premium for example).

\section{The model}

Time is discrete and goes from 0 to infinity. We first describe the final good sector, then the intermediate good sector and the research activity. Second, households behavior and equilibrium conditions are introduced.

\subsection{The final good sector}

The final good sector produces a composite good that is used either to consume or to invest in physical capital. It uses physical capital, immaterial capital and two types of labor as inputs. Each vintage of physical capital has its own embodied productivity.

\subsubsection{The problem of the firm}

Let $E_{s, t}$ represent the number of machines or capital units (hardware) produced at time $s$ (i.e., the vintage $s$ ) and still in use at time $t \geqslant s$. The quantity $I_{s}=E_{s, s}$ stands for gross investment, i.e., capital goods production at time $s$. We assume that the physical depreciation rate, $\delta$, is constant so

$$
E_{s, t}=I_{s}(1-\delta)^{t-s} .
$$

At time $t \geqslant s$, the vintage $s$ is operated by a certain amount of unskilled labor, say $L_{s, t}$, and skilled labor, say $H_{s, t}$. Let $Y_{s, t}$ be the output produced at time $t$ with vintage $s$. Under the following Cobb-Douglas technology we have

$$
Y_{s, t}=z_{t}\left(q_{s} E_{s, t}\right)^{\gamma} L_{s, t}^{\alpha} H_{s, t}^{\beta} .
$$

with $\alpha, \beta \in[0,1]$ and $\gamma=1-\alpha-\beta$. The variables $z_{t}$ and $q_{t}$ represent the state of knowledge at time $t$. An increase in $z_{t}$ rises the marginal productivity of all the capital stock, independently of its age structure. Hence, $z_{t}$ represents disembodied technological progress. In sharp contrast, $q_{s}$ is specific to the equipment of vintage $s$ and represents embodied technological progress.

We relate $q_{s}$ to the immaterial capital embodied in the vintage $E_{s, t}$. This immaterial capital is build from a series of specialized intermediate goods, following a DixitStiglitz (1977) CES function:

$$
q_{s}=\left(\int_{0}^{n_{s}} x_{i, s}^{\frac{\sigma-1}{\sigma}} \mathrm{d} i\right)^{\frac{\sigma}{\sigma-1}}
$$


$n_{s}$ is the number of varieties available in $s, x_{i, s}$ is the quantity of input used in $s$ of variety $i$ and $\sigma>1$ is the elasticity of substitution between two varieties.

Total output at time $t$, say $Y_{t}$, is the sum of outputs produced with all vintages,

$$
Y_{t}=z_{t} \sum_{s=-\infty}^{t}\left(q_{s} E_{s, t}\right)^{\gamma} L_{s, t}^{\alpha} H_{s, t}^{\beta} .
$$

The discounted profits of investing $I_{t}$ in physical equipment of vintage $t$ and in $x_{i, t}$ input of immaterial capital of variety $i$ are given by:

$$
\Pi(t)=\sum_{s=t}^{\infty}\left[Y_{t, s}-b_{s} L_{t, s}-w_{s} H_{t, s}\right] R_{t}^{s}-I_{t}-\int_{0}^{n_{t}} p_{i, t} x_{i, t} \mathrm{~d} i,
$$

where

$$
R_{t}^{t}=1 \text { and } R_{t}^{s}=\prod_{\tau=t+1}^{s}\left(\frac{1}{1+r_{\tau}}\right)
$$

is the discounted factor at time $s$ and $r_{\tau}$ is the interest rate at time $\tau . b_{s}$ and $w_{s}$ are respectively the wages for unskilled and skilled labor input at time $s . p_{i, t}$ is the price of variety $i$.

The representative firm chooses physical and immaterial investment and the labor allocation across vintages in order to maximize its discounted profits taking prices as given and subject to its technological constraint:

$$
I_{t},\left\{x_{i, t}\right\}_{i=0}^{n_{t}}, \max _{\left.L_{t, s}\right\}_{s=t}^{\infty},\left\{H_{t, s}\right\}_{s=t}^{\infty}} \Pi_{t}
$$

The first order conditions characterizing an interior maximum for $\Pi_{t}$ are

$$
\gamma q_{t}^{\gamma} I_{t}^{-\alpha-\beta} \sum_{s=t}^{\infty} R_{t}^{s} z_{s}(1-\delta)^{\gamma(s-t)} L_{t, s}^{\alpha} H_{t, s}^{\beta}=1,
$$

$\forall s \geqslant t:$

$$
\begin{aligned}
& \alpha z_{s}\left(q_{t} E_{t, s}\right)^{\gamma} L_{t, s}^{\alpha-1} H_{t, s}^{\beta}=b_{s} \\
& \beta z_{s}\left(q_{t} E_{t, s}\right)^{\gamma} L_{t, s}^{\alpha} H_{t, s}^{\beta-1}=w_{s}
\end{aligned}
$$

$\forall j \in\left[0, n_{t}\right]:$

$$
\gamma q_{t}^{-\alpha-\beta} I_{t}^{\gamma}\left[\sum_{s=t}^{\infty} R_{t}^{s} z_{s}(1-\delta)^{\gamma(s-t)} L_{t, s}^{\alpha} H_{t, s}^{\beta}\right]\left(\frac{q_{t}}{x_{j, t}}\right)^{\frac{1}{\sigma}}=p_{j, t}
$$

Equation (6) determines investment at time $t$ by equalizing marginal returns to marginal costs. Equations (7) and (8) determine the labor allocation at time $s$ to vintage $t$. Equation (9) gives is the demand function for the intermediate input of type $i$.

\subsubsection{Aggregation properties}

We define the total stock of efficient capital, which includes both material and immaterial aspects, as

$$
K_{t}=\sum_{s=-\infty}^{t} q_{s} E_{s, t}=\sum_{s=-\infty}^{t} q_{s} I_{s}(1-\delta)^{t-s} \mathrm{~d} s
$$


It is thus the sum of surviving machines weighted by their respective productivity. The productivity of each machine depends itself on the embedded immaterial capital. The corresponding law of motion of capital is

$$
K_{t}=(1-\delta) K_{t-1}+q_{t} I_{t}
$$

Note that the embodied technological progress variable $q_{t}$ can be seen as a measure of marginal productivity or efficiency of new equipment, it is endogenous in our model in contrast to the canonical model of Greenwood, Hercowitz and Krusell (1997). A previous theoretical attempt at endogenizing $q_{t}$ is in Krusell (1998). However the research sector in this contribution is extremely ad-hoc as one can see. Our specifications are much more in line with the vintage capital models of Boucekkine, del Río and Licandro (2000) and Hsieh (2000). However we rely on a much more complete setting in order to meet the basic characteristics of the IT sector as stated in the introduction, and this clearly differentiates our approach.

We next define aggregate skilled and unskilled labor demand and relate them to capital. Combining equations (7) and (8) one obtains that

$$
\alpha H_{t, s} w_{s}=\beta L_{t, s} b_{s}
$$

We next transform equations (7) and (8) into

$$
\begin{aligned}
& \beta^{\beta} \alpha^{1-\beta} z_{s}\left(q_{t} E_{t, s}\right)^{\gamma} L_{t, s}^{-\gamma}=b_{s}^{1-\beta} w_{s}^{\beta} \\
& \alpha^{\alpha} \beta^{1-\alpha} z_{s}\left(q_{t} E_{t, s}\right)^{\gamma} H_{t, s}^{-\gamma}=w_{s}^{1-\alpha} b_{s}^{\alpha}
\end{aligned}
$$

Using (13), the aggregate unskilled employment level at time $t$ is:

$$
L_{t}=\sum_{s=-\infty}^{t} L_{s, t}=\left(\frac{\beta^{\beta} \alpha^{1-\beta} z_{t}}{b_{t}^{1-\beta} w_{t}^{\beta}}\right)^{\frac{1}{\gamma}} \sum_{s=-\infty}^{t} q_{s} E_{s, t}
$$

Hence, the demand for unskilled employment can be written

$$
L_{t}=\left(\frac{\beta^{\beta} \alpha^{1-\beta} z_{t}}{b_{t}^{1-\beta} w_{t}^{\beta}}\right)^{\frac{1}{\gamma}} K_{t}
$$

and, using (12) the aggregate skilled employment level is

$$
H_{t}=\left(\frac{\alpha^{\alpha} \beta^{1-\alpha} z_{t}}{b_{t}^{\alpha} w_{t}^{1-\alpha}}\right)^{\frac{1}{\gamma}} K_{t}
$$

Replacing now $L_{s, t}$ and $H_{s, t}$ in (4) by their value taken from equations (13) and (14), one obtains:

$$
Y_{t}=z_{t}\left(\frac{\beta^{\beta} \alpha^{1-\beta} z_{t}}{b_{t}^{1-\beta} w_{t}^{\beta}}\right)^{\frac{\alpha}{\gamma}}\left(\frac{\alpha^{\alpha} \beta^{1-\alpha} z_{t}}{b_{t}^{\alpha} w_{t}^{1-\alpha}}\right)^{\frac{\beta}{\gamma}} \sum_{s=-\infty}^{t} q_{s} E_{s, t} .
$$

Equation (10), (13), (14), and (17) jointly imply that

$$
Y_{t}=z_{t} K_{t}^{\gamma} L_{t}^{\alpha} H_{t}^{\beta}
$$

Hence, if one redefines the capital stock as we did in equation (10), we retrieve a CobbDouglas production function as in Solow (1960). 


\subsubsection{The demand for intermediate inputs}

Using equations (6) and (9) the demand for intermediate input $j$ by the firms of the final good sector can be rewritten

$$
\frac{x_{j, t}}{q_{t}}=\left(\frac{I_{t}}{q_{t}}\right)^{\sigma} p_{j, t}^{-\sigma}
$$

The price elasticity of demand is thus $-\sigma$.

\subsection{The intermediate good sector}

The intermediate good sector produces a number of immaterial products that are sold to the final good sector. It uses unskilled labor to produce the goods and skilled labor to research for new varieties.

\subsubsection{The production activity}

The sector $\left[0, n_{t}\right]$ producing the intermediate goods is divided into a competitive sector $\left[0, n_{t}^{c}\right]$ and a monopolistic sector $\left.] n_{t}^{c}, n_{t}\right]$. The market power is given by the presence of copyrights which have a lifetime of $T$. Hence, after a span of time $T$, monopolistic firms become competitive and we have

$$
n_{t}^{c}=n_{t-T}
$$

The intermediate good of type $i \in\left[0, n_{t}\right]$ is produced with a constant return to scale technology involving unskilled labor as the only input:

$$
x_{i, t}=\tau \tilde{L}_{i, t}
$$

where $\tilde{L}_{i, t}$ denotes unskilled labor employed in the intermediate sector and $\tau$ measures labor productivity.

In the side of the sector that behaves competitively, the output price is equal to the marginal cost:

$$
p_{i, t}=\frac{b_{t}}{\tau}, \quad \forall i \in\left[0, n_{t}^{c}\right]
$$

In the side of the sector that behaves monopolistically, the output price is chosen so as to maximize profits subject to the demand formulated by the final good sector:

$$
\max \left(p_{i, t}-\frac{b_{t}}{\tau}\right) x_{i, t} \text { s.t. }(
$$

This leads to

$$
\left.\left.p_{i, t}=\left(1-\frac{1}{\sigma}\right)^{-1} \frac{b_{t}}{\tau}, \quad \forall i \in\right] n_{t}^{c}, n_{t}\right]
$$

and the price is a mark-up over unit labor costs, whose mark-up rate depend on the price elasticity of demand. 


\subsubsection{The research activity}

Following Grossman and Helpman (1991) and Michel and Nyssen (1998), the research activity requires labor and public knowledge. The stock of public knowledge $m_{t}$ that is used in the production of new types of input consists in the inputs being in the public domain $\left[0, n_{t}^{c}\right]$ but is also influenced by the inputs covered by copyrights. This latter influence is moderated by the parameter $\theta<1$ :

$$
m_{t}=n_{t}^{c}+\theta\left(n_{t}-n_{t}^{c}\right)
$$

The parameter $\theta$ is called the diffusion coefficient in the literature. It is equal to one when knowledge is non excludable despite the existence of copyrights. On the contrary it is equal to zero, as in Judd (1985), when copyrights prevent any positive externality from protected software to public knowledge. In this latter case, endogenous growth is made impossible.

The production of new inputs is made with skilled labor, according to the following constant return to scale technology:

$$
\Delta n_{t}=n_{t}-n_{t-1}=a m_{t} \tilde{H}_{t}
$$

and the unit cost of research $v_{t}$ is given by

$$
v_{t}=\frac{w_{t}}{a m_{t}}
$$

The unit cost increases with the skilled wage and decreases with the level of public knowledge.

There will be entry of new firms until this cost is equal to the discounted flow of profits linked to one invention. This equilibrium condition that determines the number of new firms $n_{t}$ can be written:

$$
v_{t}=\sum_{z=t}^{t+T-1} R_{t}^{z} \frac{1}{\sigma-1} \frac{b_{z}}{\tau} x_{i, z}
$$

Note that by (19) the discounted flow of profits depends on the investment made by the firms in the final goods sector. This is the main consequence of embodiment in our model: The return to research is related to investment in the final goods sector. Such a property does not arise in research-based growth models if technological progress is fully disembodied as one can infer from the models built up by Howitt and Aghion (1998) and by Boucekkine, del Río and Licandro (2000). We will see later that this characteristic of the model, featuring a kind of strategic complementarity between investment and $R \& D$, is responsible for multiple steady states to occur. ${ }^{2}$

Finally, the demand for skilled labor by the research sector is given by

$$
\tilde{H}_{t}=\frac{\Delta n_{t}}{a m_{t}}
$$

\footnotetext{
${ }^{2}$ Note that we can have an equilibrium situation where it is not profitable to invest in research. In this case we have$$
v_{t}>\sum_{z=t}^{t+T-1} R_{t}^{z} \frac{1}{\sigma-1} \frac{b_{z}}{\tau} x_{i, z}
$$

and the consequence is $n_{t}=n_{t-1}$. In this paper, we concentrate on the case where (27) holds.
} 


\subsection{Household behavior}

There are two types of households, skilled and unskilled. They both consume, save for future consumption and supply labor inelastically. The households savings are invested either in physical capital or in the research activity.

We model these households as one representative household supplying $H$ units of skilled labor and $L$ units of unskilled labor. He/she maximizes the discounted sum of instantaneous utility:

$$
\sum_{t=0}^{\infty} \rho^{t} \ln C_{t}
$$

where $\rho$ is the psychological discount factor and the utility function is logarithmic. The budget constraint is

$$
A_{t+1}=\left(1+r_{t+1}\right) A_{t}+w_{t} H+b_{t} L-C_{t}
$$

where $A_{t}$ stands for the assets detained by households. The first-order necessary condition for this problem is

$$
\frac{C_{t+1}}{C_{t}}=\left(1+r_{t+1}\right) \rho
$$

which, together with the usual transversality condition, is sufficient for an optimum.

\subsection{Market equilibrium}

Equilibrium on the skilled labor market implies the skilled labor force is employed in the final good sector or in the research sector:

$$
H=H_{t}+\tilde{H}_{t}
$$

Equilibrium on the unskilled labor market implies the the unskilled labor force is employed in the final good sector or in the intermediate good sector:

$$
L=L_{t}+\int_{0}^{n_{t}} \tilde{L}_{i, t} \mathrm{~d} i
$$

Equilibrium on the final good market implies

$$
Y_{t}=C_{t}+I_{t}
$$

which, after using the budget constraints of the agents, is equivalent to

$$
\Delta A_{t+1}=I_{t}+v_{t} \Delta n_{t},
$$

i.e. savings finance either investment in physical capital or in research.

\section{The equilibrium}

In this section we characterize the equilibrium and give some analytical characterization of a balanced growth path. 


\subsection{Characteristics}

We begin by stating a proposition summarizing the equilibrium and optimality conditions of the model. The proof is reported in Appendix A.

Proposition 1 Given the initial conditions $K_{-1}$ and $\left\{n_{t}\right\}_{t=-T .-1}$, an equilibrium is a path

$$
\left\{w_{t}, b_{t}, q_{t}, I_{t}, K_{t}, r_{t+1}, n_{t}, C_{t}, m_{t}\right\}_{t \geqslant 0}
$$

that satisfies the following conditions:

$$
\begin{aligned}
& L=\left(\frac{\beta^{\beta} \alpha^{1-\beta} z_{t}}{b_{t}^{1-\beta} w_{t}^{\beta}}\right)^{\frac{1}{\gamma}} K_{t}+\left(n_{t-T}+\left(1-\frac{1}{\sigma}\right)^{\sigma}\left(n_{t}-n_{t-T}\right)\right)\left(\frac{\tau I_{t}}{b_{t}}\right)^{\sigma} q_{t}^{1-\sigma} \\
& H=\left(\frac{\alpha^{\alpha} \beta^{1-\alpha} z_{t}}{b_{t}^{\alpha} w_{t}^{1-\alpha}}\right)^{\frac{1}{\gamma}} K_{t}+\frac{\Delta n_{t}}{a m_{t}} \\
& z_{t}^{\frac{1}{\gamma}} K_{t}\left(\frac{\alpha}{b_{t}}\right)^{\frac{\alpha}{\gamma}}\left(\frac{\beta}{w_{t}}\right)^{\frac{\beta}{\gamma}}=C_{t}+I_{t} \\
& \gamma q_{t} z_{t}^{\frac{1}{\gamma}}\left(\frac{\alpha}{b_{t}}\right)^{\frac{\alpha}{\gamma}}\left(\frac{\beta}{w_{t}}\right)^{\frac{\beta}{\gamma}}=1-\frac{(1-\delta) q_{t}}{\left(1+r_{t+1}\right) q_{t+1}} \\
& \frac{C_{t+1}}{C_{t}}=\left(1+r_{t+1}\right) \rho \\
& K_{t}=(1-\delta) K_{t-1}+q_{t} I_{t} \\
& \frac{b_{t} q_{t}}{\tau I_{t}}=\left(n_{t-T}+\left(n_{t}-n_{t-T}\right)\left(1-\frac{1}{\sigma}\right)^{\sigma-1}\right)^{\frac{1}{\sigma-1}} \\
& \frac{\tau^{1-\sigma}(\sigma-1)^{1-\sigma} \sigma^{\sigma}}{a}\left(\frac{w_{t}}{m_{t}}-\frac{R_{t}^{t+1} w_{t+1}}{m_{t+1}}\right)=b_{t}^{1-\sigma} I_{t}^{\sigma} q_{t}^{1-\sigma}-R_{t}^{t+T} b_{t+T}^{1-\sigma} I_{t+T}^{\sigma} q_{t+T}^{1-\sigma} \\
& m_{t}=(1-\theta) n_{t-T}+\theta n_{t}
\end{aligned}
$$

Equations (33), (34) and (35) describe the equilibrium on the unskilled labor, skilled labor and final goods markets respectively. The equilibrium interest rate obtains from (36). Optimal consumption is given in equation (37). Equation (38) is the accumulation rule of capital. Equation (39) links the embodied technological progress to the expansion in the varieties of intermediate products. Equation (40) is derived from the free entry condition. 


\subsection{The balanced growth path}

We assume that labor supplies $L$ and $H$ are constant. The disembodied technological progress $z_{t}$ is also assumed constant in the long-term.

Along a balanced growth path, each variable grows at a constant rate. For output we have

$$
Y_{t}=\bar{Y} g_{Y}^{t}
$$

where $g_{Y}$ is the growth factor and $\bar{Y}$ the initial level of output. $n_{t}, C_{t}, I_{t}, q_{t}, b_{t}, w_{t}$ and $K_{t}$ grows respectively with factors $g_{n}, g_{C}, g_{I}, g_{q}, g_{b}, g_{w}$ and $g_{K}$. The interest rate $r_{t}$ is constant.

Proposition 2 If $q_{t}$ grows at a rate $g_{q}>1$, then all the other variables grow at strictly positive rates with

$$
\begin{aligned}
g_{n} & =g_{q}^{\sigma-1} \\
g_{Y}=g_{C}=g_{I}=g_{w}= & g_{b}=g_{q}^{\frac{\gamma}{1-\gamma}} \\
g_{K} & =g_{q}^{\frac{1}{1-\gamma}}
\end{aligned}
$$

Proof: If a balanced growth path should satisfy the nine equations (33)-(41), then one should have the following eight restrictions among the various growth rates:

$$
\begin{aligned}
& \left(g_{b}\right)^{\frac{-(1-\beta)}{\gamma}}\left(g_{w}\right)^{\frac{-\beta}{\gamma}} g_{K}=1=\frac{g_{N}}{g_{q}}\left(\frac{g_{s}}{g_{b}}\right)^{\sigma} \\
& g_{K}=\left(g_{b}\right)^{\frac{\alpha}{\gamma}}\left(g_{w}\right)^{\frac{1-\alpha}{\gamma}} \\
& g_{K}=g_{Y}\left(g_{b}\right)^{\frac{\alpha}{\gamma}}\left(g_{w}\right)^{\frac{\beta}{\gamma}} \\
& g_{q}=\left(g_{b}\right)^{\frac{\alpha}{\gamma}}\left(g_{w}\right)^{\frac{\beta}{\gamma}} \\
& g_{N}^{\frac{\sigma}{1-\sigma}}=\left(\frac{g_{Y}}{g_{b} g_{q}}\right)^{\sigma} \rho \\
& g_{Y}=(1+r) \rho \\
& g_{K}=g_{q} g_{Y} \\
& \frac{g_{w}}{g_{N}}=g_{b}^{1-\sigma} g_{q}^{1-\sigma} g_{Y}^{\sigma} \\
& g_{m}=g_{N}
\end{aligned}
$$

We use implicitly the condition $g_{Y}=g_{C}=g_{I}$ in (45)-(52), a condition implied by the good market equilibrium and by the fact that the share of consumption in production cannot tend to zero or to infinity along a balanced growth path. Using (45) and (46) to eliminate $g_{K}$ we have $g_{b}=g_{w}$. The (48) gives:

$$
g_{b}=g_{w}=g_{q}^{\frac{\gamma}{1-\gamma}},
$$


and by (46), $g_{K}=g_{q}^{\frac{1}{1-\gamma}}$. Equation (47) yields $g_{Y}=g_{q}^{\frac{\gamma}{1-\gamma}}$. It turns out that (51) is redundant with (47). Now, by using (49) we get

$$
g_{N}=\left(\frac{g_{Y}}{g_{b} g_{q}}\right)^{1-\sigma} .
$$

This result is the same obtained from equation (52):

$$
\frac{g_{w}}{g_{N}}=g_{b}^{1-\sigma} g_{q}^{1-\sigma} g_{Y}^{\sigma}
$$

Hence, the two latter equations are redundant with (49). At the end, the seven unknown of the problem $\left(g_{b}, g_{w}, g_{q}, g_{Y}, g_{N}, g_{K}, \bar{r}\right)$ are shown to be truly related by a system of six equations (out of the nine initial restrictions since three redundant equations have been identified). For given $g_{q}$, all the other unknowns can be found. They are thus parameterized by $g_{q}$, including $\bar{r}$ since by (50), we have $\bar{r}=g_{q}^{\frac{\gamma}{1-\gamma}} / \rho-1$. QED

Hence, along a balanced growth path, output, consumption, investment and wages grow at the same rate. The stock of capital grows faster as it includes improvement in the embodied productivity. To determine $g_{q}$, we need an additional information, which is provided by the restrictions on the long-run levels. Computing these restrictions from the dynamic system (33)-(40) we end with 8 equations for 9 unknowns $(\bar{w}$, $\bar{b}, \bar{n}, \bar{q}, \bar{I}, \bar{C}, \bar{K}, \bar{r}$ and $g_{q}$ ) since all the other growth rates can be expressed in terms of $g_{q}$. The system in terms of levels is therefore undetermined, which is a usual property of endogenous growth models. Fortunately, it is always possible to rewrite this system in such way that we get rid of this indeterminacy. As usual, this is done by "stationarizing" the equations by the means of some auxiliary variables. Indeed, the dynamic system (33)-(40) can be rewritten as a function of eight stationary variables, which are

$$
r_{t}, \quad \hat{w}_{t}=\frac{w_{t}}{b_{t}}, \quad \hat{K}_{t}=\frac{K_{t}}{n_{t}^{\frac{1}{(1-\gamma)(\sigma-1)}}}, \quad \hat{C}_{t}=\frac{C_{t}}{b_{t}}, \quad \hat{I}_{t}=\frac{I_{t}}{b_{t}}, \quad \hat{q}_{t}=\frac{q_{t}}{b_{t}^{\frac{1-\gamma}{\gamma}}}, \quad g_{t}=\frac{n_{t}}{n_{t-1}}, \hat{n}_{t}=\frac{n_{t}}{b_{t}^{\frac{(1-\gamma)(\sigma-1)}{\gamma}}},
$$

and $\hat{m}_{t}=\frac{m_{t}}{n_{t}}$.The stationarized dynamic system is given in appendix B. Note that as for the original system, we have two pre-determined variables $\hat{K}_{t}$ and $\hat{g}_{t}$. Hence our stationarization does not alter the dynamic order of the original system. The corresponding steady state system is summarized in the following proposition.

Proposition 3 Denote $g_{n}=g$ and $\alpha_{1}=(\sigma-1)(1-\gamma)$. Considering that $\lim z_{t}=z$ and defining the following stationary variables,

$$
\hat{w}=\frac{\bar{w}}{\bar{b}}, \quad \hat{K}=\frac{\bar{K}}{\bar{n}^{\frac{1}{\alpha_{1}}}}, \hat{C}=\frac{\bar{C}}{\bar{b}}, \quad \hat{I}=\frac{\bar{I}}{\bar{b}}, \quad \hat{q}=\frac{\bar{q}}{\bar{b}^{\frac{1-\gamma}{\gamma}}}, \hat{n}=\frac{\bar{n}}{\bar{b}^{\frac{(1-\gamma)(\sigma-1)}{\gamma}}},
$$

the restrictions on the levels can be rewritten as

$$
\begin{aligned}
&\left(\frac{\beta^{\beta} \alpha^{1-\beta} z}{\hat{w}^{\beta}}\right)^{\frac{1}{\gamma}} \hat{K} \hat{n}^{\frac{1}{\alpha_{1}}}+\left(g^{-T}+\left(1-\frac{1}{\sigma}\right)^{\sigma}\left(1-g^{-T}\right)\right)(\tau \hat{I})^{\sigma} \hat{q}^{1-\sigma} \hat{n}=\quad L \\
&\left(\frac{\alpha^{\alpha} \beta^{1-\alpha} z}{\hat{w}^{1-\alpha}}\right)^{\frac{1}{\gamma}} \hat{K} \hat{n}^{\frac{1}{\alpha_{1}}}+\frac{1-1 / g}{a\left(g^{-T}+\theta\left(1-g^{-T}\right)\right)}=H
\end{aligned}
$$




$$
\begin{aligned}
z^{\frac{1}{\gamma} \hat{K} \hat{n}^{\frac{1}{\alpha_{1}}}} \alpha^{\frac{\alpha}{\gamma}}\left(\frac{\beta}{\hat{w}}\right)^{\frac{\beta}{\gamma}} & =\hat{C}+\hat{I} \\
\gamma \hat{q} z^{\frac{1}{\gamma}} \alpha^{\frac{\alpha}{\gamma}}\left(\frac{\beta}{\hat{w}}\right)^{\frac{\beta}{\gamma}}+\frac{1-\delta}{(1+r)} g^{\frac{-1}{\sigma-1}} & =1 \\
g^{\frac{\gamma}{\alpha_{1}}}= & (1+r) \rho \\
\hat{K}\left(1-(1-\delta) g^{\frac{-1}{\alpha_{1}}}\right) & =\quad \hat{q} \hat{I} \hat{n}^{\frac{-1}{\alpha_{1}}} \\
g^{-T}+\left(1-g^{-T}\right)\left(1-\frac{1}{\sigma}\right)^{\sigma-1} & =\left(\frac{\hat{q}}{\tau \hat{I}}\right)^{\sigma-1} \frac{1}{\hat{n}} \\
\frac{\tau^{1-\sigma}(\sigma-1)^{1-\sigma} \sigma^{\sigma} \hat{w}}{a\left((1-\theta) g^{-T}+\theta\right)}\left(1-\frac{g^{\frac{\gamma}{\alpha_{1}}-1}}{1+r}\right)-\hat{I}^{\sigma} \hat{q}^{1-\sigma} \hat{n}\left(1-\left(\frac{g^{\frac{\gamma}{\alpha_{1}}-1}}{1+r}\right)^{T}\right) & =0
\end{aligned}
$$

Note that since the other growth rates $g_{q}, g_{K}, g_{w}$ and $g_{Y}$ depend on $g_{n}=g$ through (42)-(44), this system determines all the growth rates of the variables of the model, together with seven other ratios, namely $\bar{r}, \hat{w}, \hat{K}, \hat{C}, \hat{I}, \hat{q}$ and $\hat{n}$. Our choice of stationarization is indeed the simplest algebraically speaking given the long run relationships described in Proposition 2. Obviously, we can recover any relevant stationary ratio from the seven previous one. For example, the ratio consumption to output can be simply computed as $\frac{\hat{C}}{\hat{C}+\hat{I}}$.

Given the complexity of the long run steady state described above, it is impossible to derive an analytical solution. However, though the corresponding system of equations is indeed extremely heavy to manipulate, it is possible to bring out some interesting intermediate results which turn out to be crucial to understand the issues related to the existence and uniqueness of steady state growth paths in our model. In particular, the following proposition reveals most useful.

Proposition 4 At any growth rate value $g$, there exist explicit functions expressing the long run level $\hat{K}, \hat{I}, \hat{r}, \hat{C}, \hat{q}, \hat{n}$ and $\hat{w}$ exclusively in terms of $g: \hat{K}=\Psi_{K}(g), \hat{I}=\Psi_{I}(g), \hat{r}=\Psi_{r}(g)$, $\hat{C}=\Psi_{C}(g), \hat{q}=\Psi_{q}(g), \hat{n}=\Psi_{n}(g)$ and $\hat{w}=\Psi_{w}(g)$.

It follows the obvious corollary:

Corollary 1 There exists an explicit function $\Psi(g)$ such that the long run equilibrium growth rate value solves the equation $\Psi(g)=0$.

Clearly if Proposition 4 holds, then we can obtain an explicit equation involving only $g$ by using the g-functional expressions of the long run levels in any equation of the steady state system. Therefore we can reduce our 8-dimensional system to an explicit scalar equation involving the growth rate $g$. Once this equation is solved, the remaining long run levels can be recovered using the explicit g-functions of Proposition 4. A proof of Proposition 4 can be found in Appendix C. The proof of the following useful property can be also found in the same appendix. 
Proposition 5 Assuming that a solution for the steady state system exists, the long value of $z$ only affects the stationary values $\hat{n}, \hat{q}$ and $\hat{K}$.

The property above is particularly useful in the interpretation of the outcomes of permanent shocks on the disembodied technological progress variable $z_{t}$, which is one of the main experiments conducted in the dynamics section. Proposition 5 implies in particular that a permanent change in the level of disembodied technological progress $z_{t}$ will not affect the long run growth rate of the economy. Interestingly it only affects the long run levels of the variables related to embodied technological progress such as $n_{t}$ and $q_{t}$ (stationarized by an adequate measure of raw labor cost). This suggests that permanent movements in $z_{t}$ will call for optimal responses in the embodied component of technological progress. We will come back to these issues later on. We focus right now on the existence and uniqueness of the steady state.

As argued in the introduction, our model can generate multiple steady state as it entails a clear strategic complementarity due to the embodiment hypothesis: Investment in physical capital and R\&D efforts are complementary. Although we can find by Corollary 1 an explicit equation $\Psi(g)=0$ giving the eventual steady state growth rate(s), this equation is unsurprisingly so complicated- as it summarizes the algebra of 8 nonredundant equations- that no exact solution(s) can be found out. So we resort to numerical resolution using various parameterizations. As expected, it turns out that our model can yield one steady state, two steady states or no steady state at all.

Consider the following calibration or the model. A first set of parameters is fixed a priori to what we view as reasonable values given the empirical evidence available. The skilled population is $10 \%$ of total population (roughly the share of workers with higher education is developed countries). The length of copyrights is set at five years. It means that the profits made on software invented five years ago falls to zero. The total factor productivity in the final sector is normalize to 1 . The rate of depreciation of physical capital is $4 / 100$ and the psychological discount factor is $97 / 100$.

\begin{tabular}{lcc}
\multicolumn{1}{c}{ Parameters fixed a priori } & & \\
Parameter & symbol & value \\
\hline Unskilled labor supply & $L$ & 9 \\
Skilled labor supply & $H$ & 1 \\
Copyrights length & $T$ & 5 \\
Total factor productivity in the final sector & $z$ & 1 \\
Rate of depreciation of capital & $\delta$ & .04 \\
Psychological discount factor & $\rho$ & .97 \\
\hline
\end{tabular}

A second set of parameters is fixed in order to match a series of moments of the steady state we consider. The parameters $\alpha$ and $\beta$ are such that the share of labor in the final sector is $70 \%$ and the ratio of the two wages about 3.5. The total factor productivity in the research sector $a$ is set in order to obtain a growth rate of embodied technological progress around $2 \%$. We select the elasticity of substitution between 
Figure 1.1. Bifurcation diagram: $g$ as a function of $\theta$

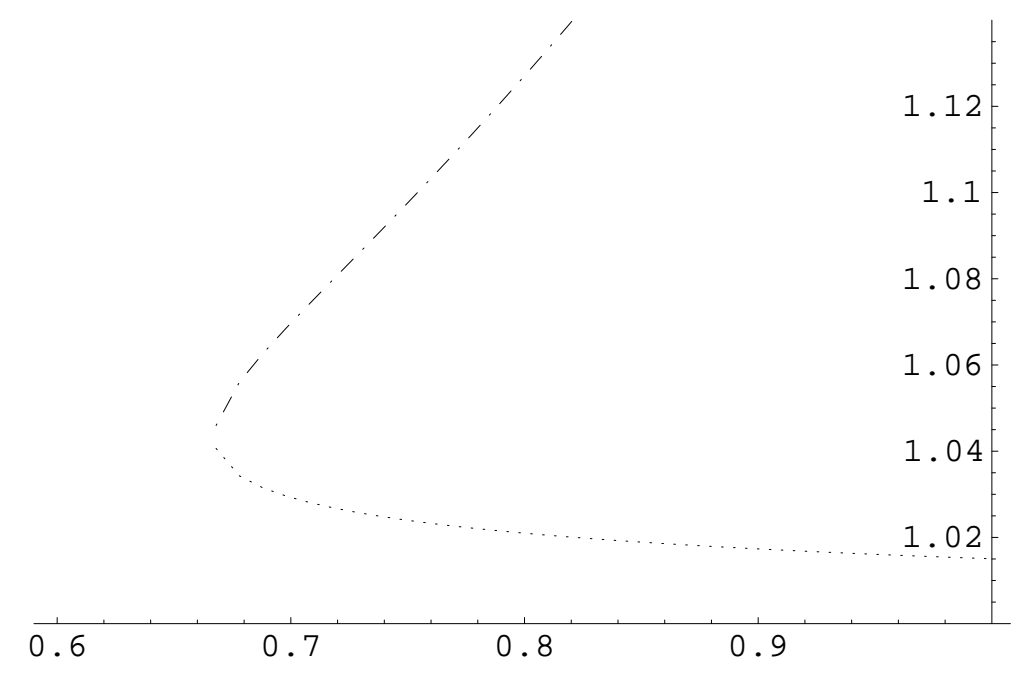

varieties of softwares to obtain a mark-up rate of 1.5. Finally the unskilled labor productivity in the intermediate sector is such that the share of unskilled workers in this sector is about $4 \%$.

\begin{tabular}{lcc}
\multicolumn{1}{c}{ Other parameters } & & \\
Parameter & symbol & value \\
\hline Unskilled labor share in the final sector & $\alpha$ & $1 / 2$ \\
Skilled labor share in the final sector & $\beta$ & $1 / 5$ \\
Total factor productivity in the research sector & $a$ & 1.2 \\
Elasticity of substitution between varieties of softwares & $\sigma$ & 3 \\
Unskilled labor productivity in the intermediate sector & $\tau$ & .1 \\
\hline
\end{tabular}

As far as the remaining parameter $\theta$ is concerned, we proceed to a more complete analysis of its role. Let this diffusion parameter vary from 0 to 1 . Figure 1.1 gives the solutions to the equation $\Psi(g)=0$ when $\theta$ varies. As one can see, for a sufficiently high diffusion rate, two equilibria arise: As expected, multiple equilibria do occur in our model. If the diffusion parameter is not enough big, no positive steady state growth rate solves the equation $\Psi(g)=0$ : Long run growth is not possible. By computing the eigenvalues of the linearized model around the steady states, we are able to assess the (local) stability of each equilibrium. ${ }^{3}$ The eigenvalues of the two steady states are depicted in figure 1.2, with their real part on the horizontal axis and their imaginary part on the vertical axis. The presence of complex eigenvalues reveals an oscillatory dynamic behavior. It turns out that the high equilibrium is stable while the low is saddle-point, both in the sense of Blanchard and Kahn (1980). Figure 1.1 thus features a saddle-node bifurcation. The same type of outcomes can be obtained if some other parameters are allowed to vary. The following table provides some characterization of

\footnotetext{
${ }^{3}$ For dynamic simulation as well as for stability assessment, we use the Dynare package designed by Juillard (1996).
} 
Figure 1.2. Eigenvalues for $\theta=0.8$

Low balanced growth path

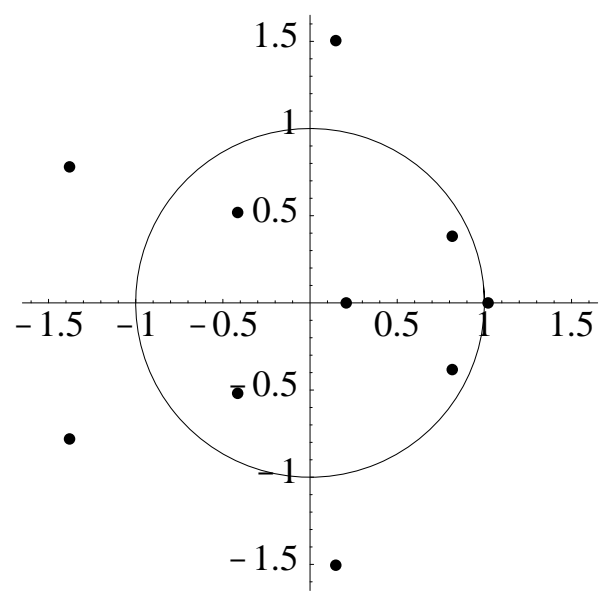

High balanced growth path

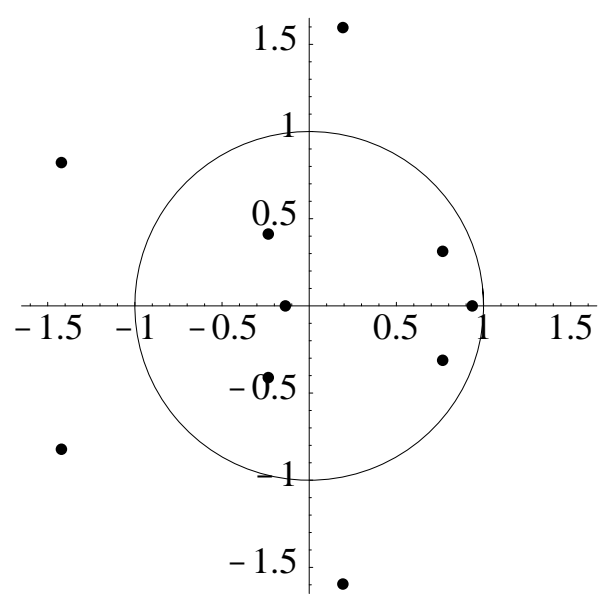

the two equilibria at $\theta=.8$. Clearly, the high equilibrium displays higher investment in both physical and immaterial capital. It also has a higher skilled premium, a higher rate of return and a much higher proportion of skilled persons working in the research sector.

\begin{tabular}{ccccccc}
$g_{q}$ & $I / Y$ & $w / b$ & $r$ & $\tilde{H} / H$ & $\tilde{L} / L$ & local stability \\
\hline $2.1 \%$ & $21.3 \%$ & 3.56 & $4.01 \%$ & $3 \%$ & $3.9 \%$ & saddle \\
$12.7 \%$ & $26.6 \%$ & 4.19 & $8.51 \%$ & $17.7 \%$ & $4.2 \%$ & node
\end{tabular}

Since stability in the sense of Blanchard-Kahn involve an infinity of stable solution paths, we will focus on the saddle-point equilibrium hereafter.

\section{Supply shocks, embodiment and dynamics}

In this section, we study the response of the system to transitory and permanent changes in the level of disembodied technological progress $z$. In order to mimic the first oil shock, we study adverse shocks. The simulated dynamic system is given in appendix B. The simulations are performed using the methodology proposed by Boucekkine (1995) for saddle-point trajectories. We consider the calibration given above with $\theta=$ 0.9 and we initialize the economy at the available saddlepoint equilibrium. We consider three types of adverse supply shocks: Non-anticipated, occurring only at $t=1$; transitory shocks affecting the economy from $t=1$ to $t=5$; and permanent shocks. In all cases, the level of disembodied technological falls down by a small amount of $0.5 \%$. The main objective of these experiments is to investigate how the economy responds on its "embodied technological progress" margin to these adverse shocks. Here are the fundamental results. 
GAUSS Tue Jul 25 16:24:47 2000

Fig 2.1 Skilled labor fraction in R\&D, shock at $t=1$

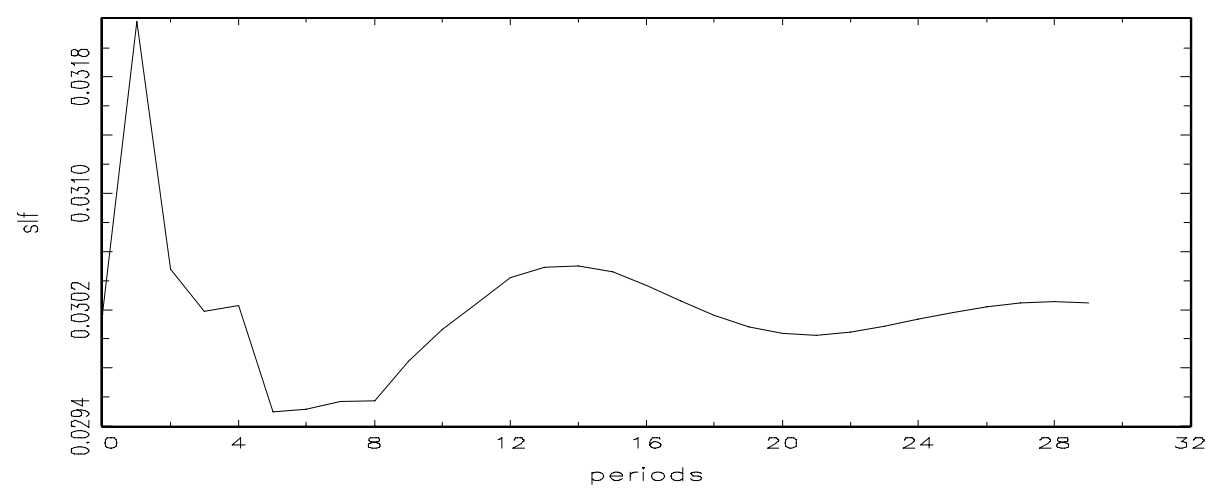

GAUSS TuE Jul 25 16:24:47 2000

Fig 2.2 Growth rate of the number of softwares, shock at $t=1$

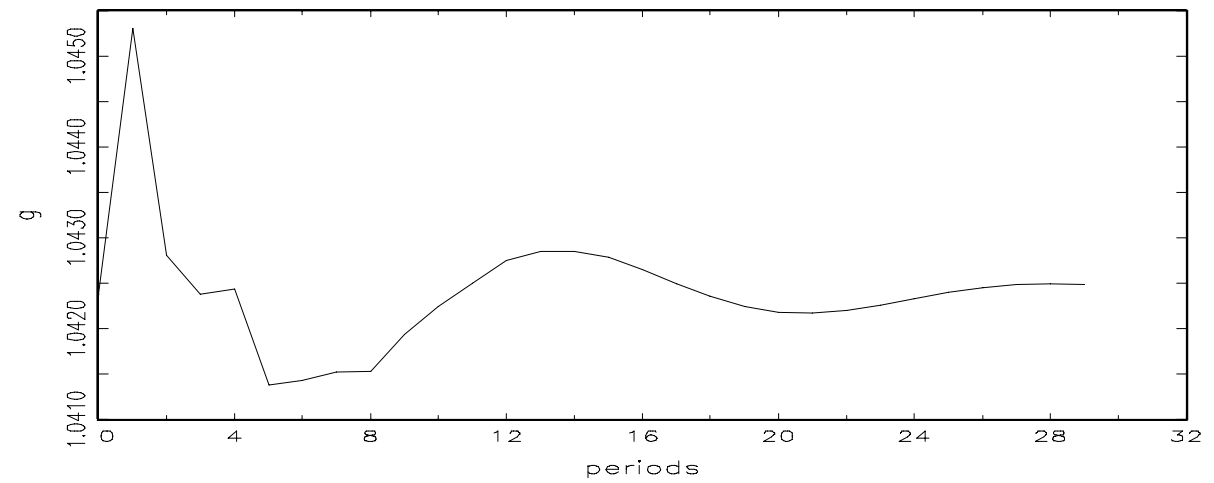

Gauss Tue Jul 25 16:24:47 2000

Fig 2.3 Unskilled labor fraction in intermediate sector, shock at $t=1$

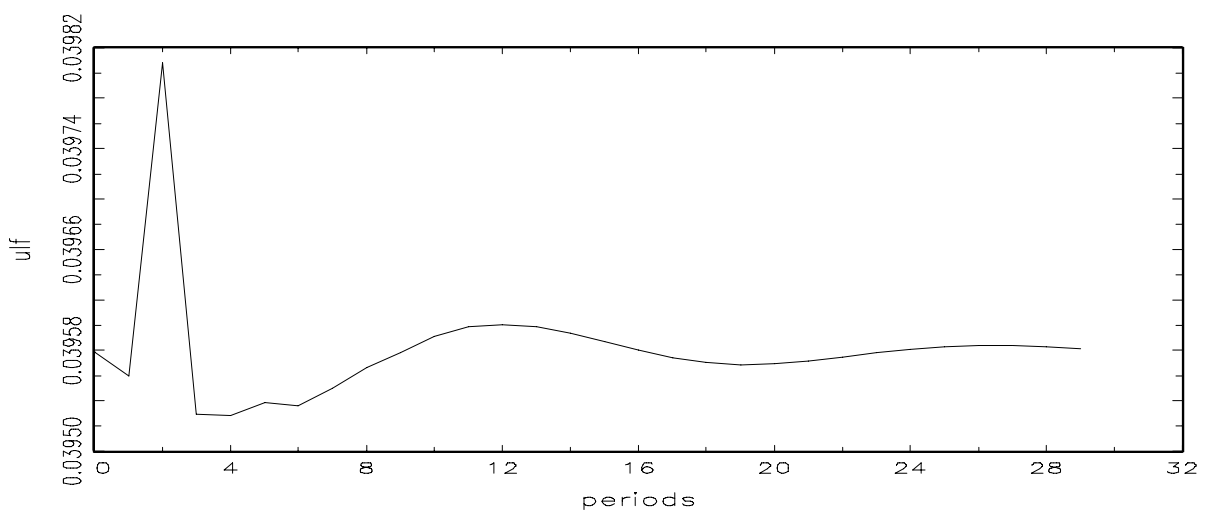




\subsection{Substitution effects}

One important argument put forward to get through the Solow paradox builds on the interpretation that the current boom of IT consists mainly in a vast substitution of IT equipment for other forms of capital and labor. This is basically the claim of Gordon (2000). An obvious way to test this claim within our model is to study how labor resources are allocated after the adverse supply shocks. Figure 2.1 gives the evolution of the skilled labor fraction devoted to research (ie, to the creation of new softwares) after an adverse shock occurring only at $t=1$. The substitution effect at the expense of the final goods sector is clear: The fraction of skilled workers doing research rises from $3 \%$ in the steady state to $3.2 \%$ at $t=1$. More skilled people devoted to research means an acceleration in the creation of softwares as it is reflected in Figure 2.2 which displays the dynamics of the growth rate of the number of softwares.

However, mainly because the shock is transitory and the economic agents know this, the economy does not become totally IT-oriented after the adverse shock. To get this point, let us have a look at Figure 2.3 which gives the dynamics of the unskilled labor fraction assigned to the production of softwares. It clearly appears that this fraction slightly decreases at $t=1$, before strongly shifting upward the next period. The ration behind this behavior as usual in the models with intertemporal consumption decisions is the following: As the adverse shock only occurs at $t=1$, the economy will try to maintain the consumption level before the shock (consumption smoothing motive). One way to avoid a bigger cut in consumption after the negative supply shock, is certainly not to assign more unskilled workers to the production of softwares and to maintain them in the final goods sector. This is clearly what happens in our experiment: The boom in the production of softwares is delayed by one period once the disembodied technological progress level recovers its stationary value.

To check the consistency of our arguments just above, we run a simulation with a permanent adverse shock. Figures 3.1 to 3.3 display the dynamics of the skilled labor fraction devoted to research, the growth rate of the number of softwares, and the fraction of unskilled labor devoted to the production of softwares. Note that by Proposition 5, such a shock will not affect the long run equilibrium of the latter variables. However short run dynamics do take place. Since the shock is permanent, the economy will cut its production accordingly and therefore it becomes clearly IT-oriented in the short run. More softwares are produced, more researchers are devoted to create new softwares and more unskilled people are assigned to their production. But as the value of $z$ does not affect the steady state equilibrium values of the latter variables, the "IT-revolution" is obviously not everlasting.

\subsection{Embodiment and labor productivity slowdown}

The theoretical studies devoted to the link between embodied technological change and labor productivity slowdown are now numerous. As pointed out in the introduction, the fundamental contributions dealing with this issue treat the former variable as exogenously given (see specially Greenwood and Yorukoglu, 1997). Since embodied technological progress is endogenous in our model, an interesting issue concerns the behavior of labor marginal productivity in the transition dynamics. Obviously it is an 
$-19-$

GALSS Tue Jut 25 16:44:07 2000

Fig 3.1 Skilled labor fraction in R\&D, permanent shock

$\frac{4}{\omega}$

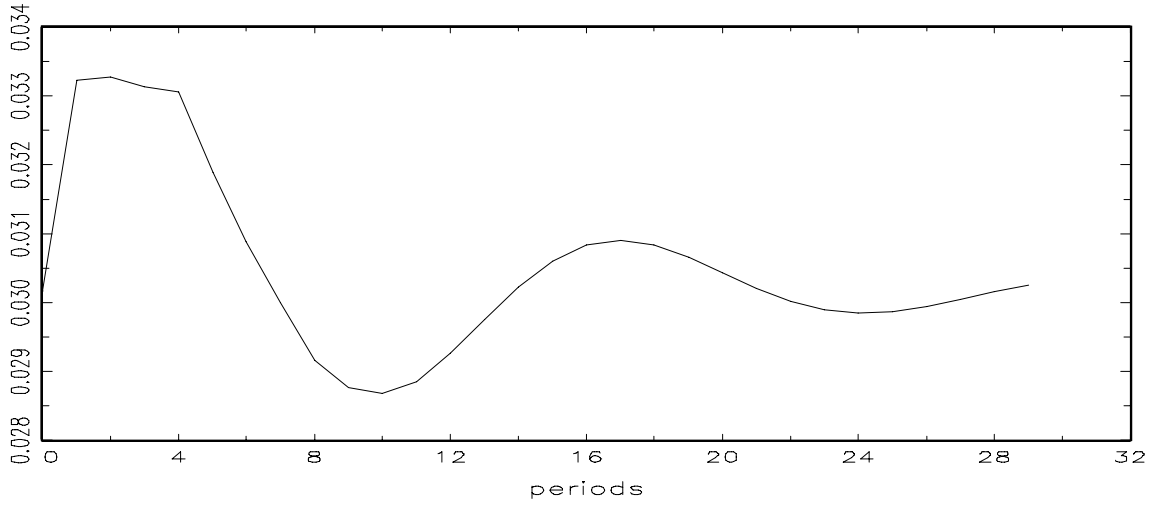

gauss Tue Jul 25 15:44:07 2000
Fig 3.2 Growth rate of the number of software, permanent shock

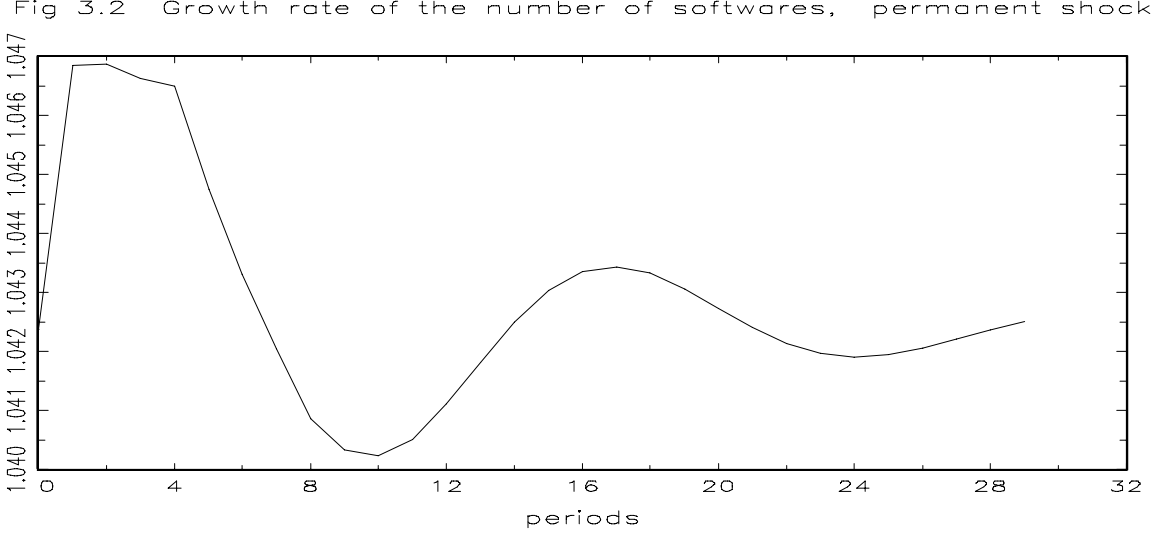

gauss Tue Jul 25 15:44:07 2000
Fig 3.3 Unskilled labor fraction in intermediate sector, permanent shoe

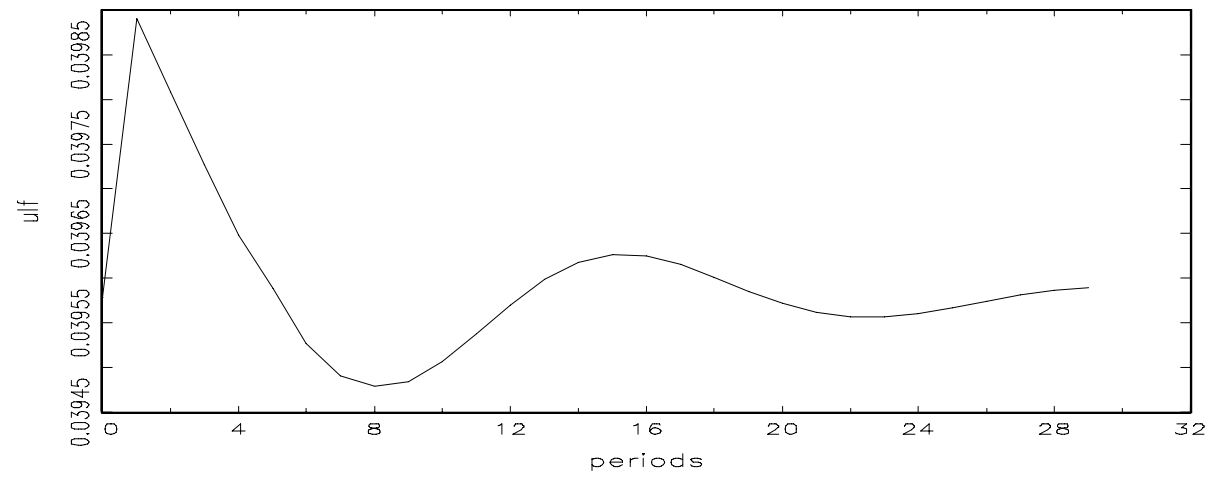



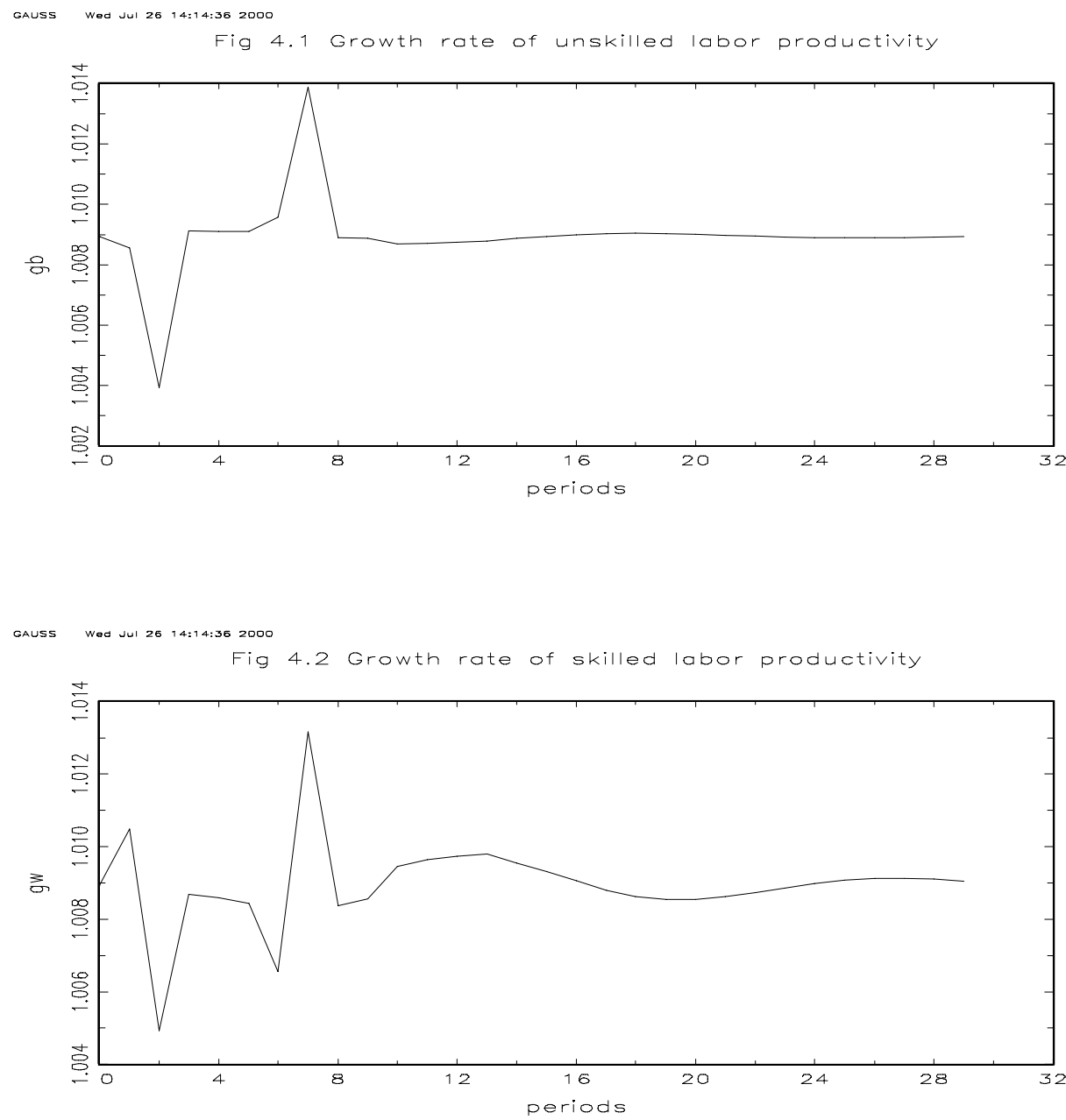

issue if we consider the final goods sector, and not the other two sectors which have linear production functions. And it is an interesting issue in the final goods sector because it amounts to study how embodiment balances the negative effects of the shock on labor productivity. Recall that by equations (6) and (7), the marginal productivity of unskilled (Resp. skilled) labor in the latter sector is measured by $b_{t}$ (Resp. $w_{t}$ ). We can compute a series for the growth rate of both $b_{t}$ and $w_{t}$ using the solutions of the simulated stationarized dynamic system. Indeed after some tedious algebraic operations, one can obtain

$$
g_{t}^{b}=\frac{b_{t}}{b_{t-1}}=\left(\frac{\hat{n}_{t-1}}{\hat{n}_{t}}\right)^{\frac{\gamma}{(1-\gamma)(\sigma-1)}} g_{t}^{\frac{\gamma}{(1-\gamma)(\sigma-1)}} .
$$

The growth rate of $w_{t}$ can be trivially deduced from $g_{t}^{b}$ and $\hat{w}_{t}$. Figures 4.1 and 4.2 give the evolution of unskilled and skilled labor marginal productivity respectively when an adverse shock affects the economy reducing the value of $z$ by $0.5 \%$ from $t=1$ to $t=5$. The productivity growth of unskilled labor worsens markedly after the shock, reaching its trough at $\mathrm{t}=2$. As for skilled labor, things are less monotonic. However, although productivity gains increase at $t=1$, they decrease sharply afterwards reach- 
$-21-$

GALSS TUE Jut 25 17:03:19 2000

Fig 4.3 Skilled labor fraction in R\&D, shock from $t=1$ to 5

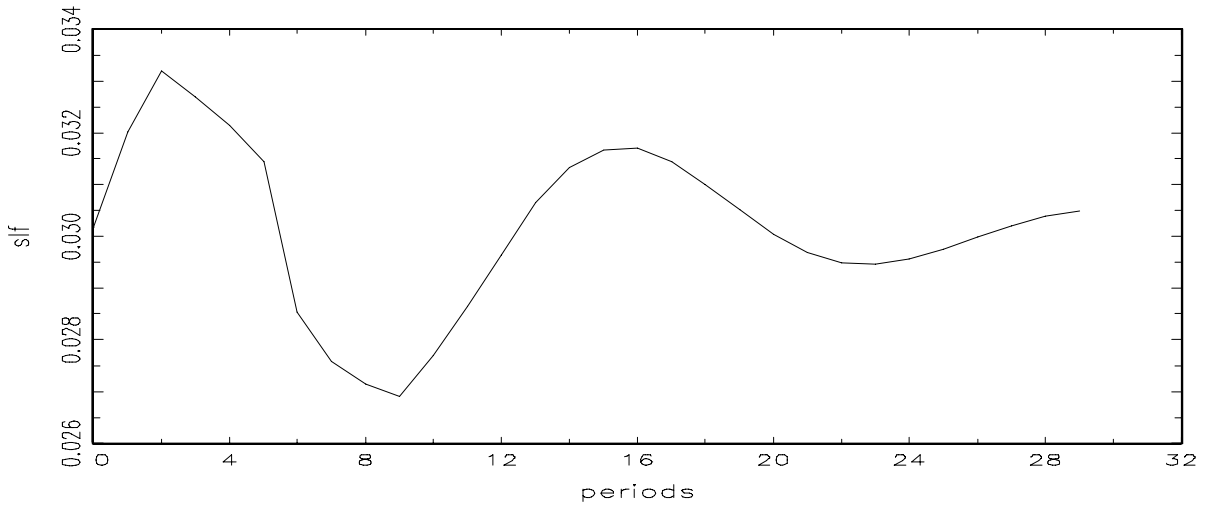

gauss Tue Jul $25 \quad 17: 03: 19 \quad 2000$

Fig 4.4 Growth rate of number of software, shock from $t=1$ to 5

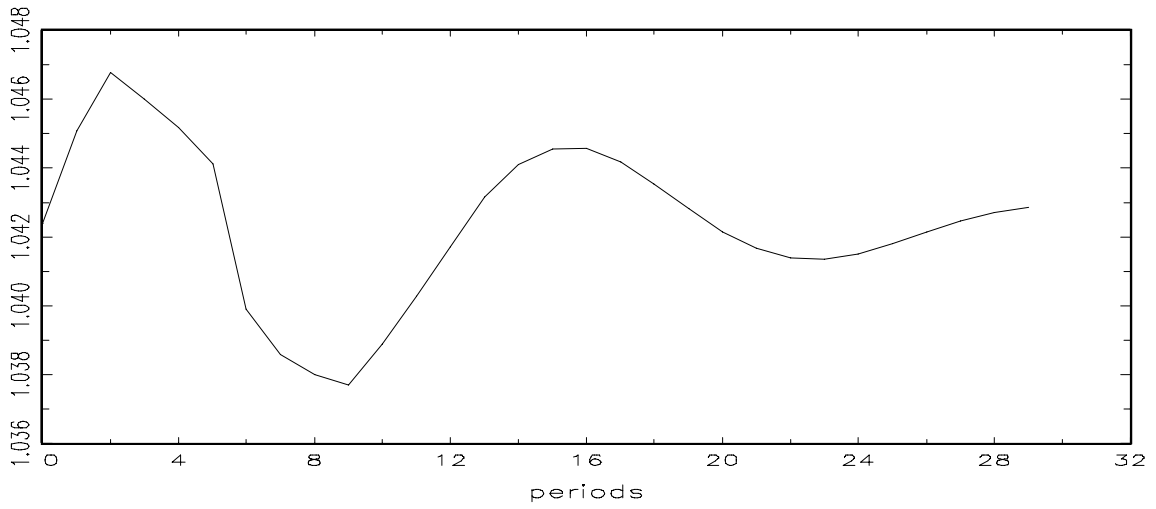

GAUSS The Jul 25 17:03:19 2000

Fig 4.5 Unskilled labor in intermediate sector, shock from $t=1$ to 5

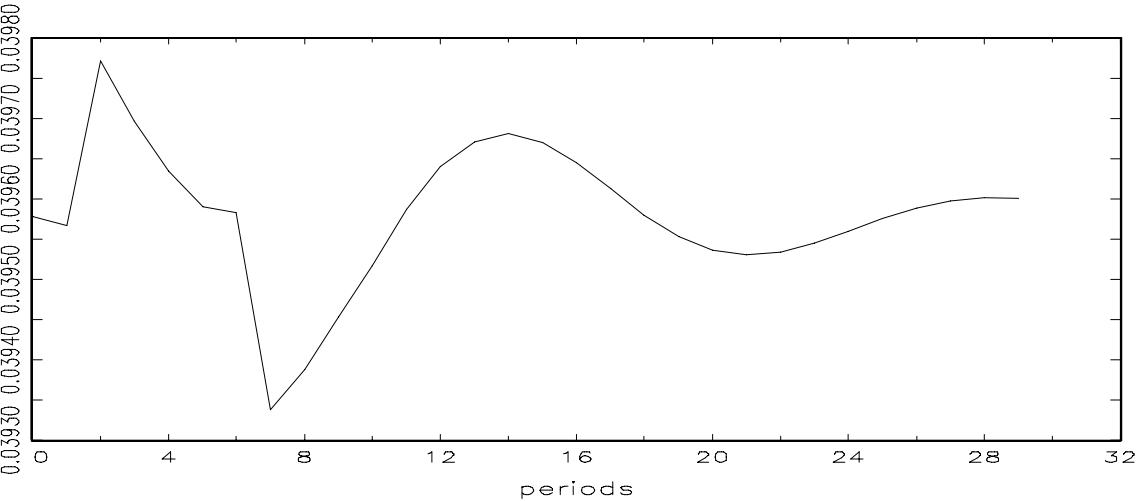


ing their trough also at $t=2$. Taking into account the relative weight of each type of labor in total labor resources of the final goods sector and the registered quantitative characteristics of the transition paths, the productivity slowdown is therefore clear and it lasts approximately as long as the adverse shock hits the economy. The IT sectors are consequently unable to balance the negative effects of the supply shock on labor productivity growth in the final goods sector. To understand why the productivity slowdown in the final goods sector is so important at $t=2$, Figures 4.3 to 4.5 are most helpful. Indeed, at $t=2$, the fraction of skilled people assigned to research and the fraction of unskilled people assigned to the intermediate goods sector attain their respective maxima, together with the growth rate of the number of softwares. So at this date, the allocation of labor resources is particularly bad for the final goods sector, which shows up clearly in the dynamics of labor marginal productivity.

\subsection{The skill premium, the value of research and the interest rate}

One of the most interesting debates around the IT revolution concerns the skill premium that presumably increases in the information age. There is a huge literature on this topic starting from the capital-skill complementarity hypothesis advocated by Griliches (1969). Admittedly the skill premium increases in periods of sharp technical change since skilled workers have a comparative advantage in running the new technologies but this premium tends to vanish as the innovations get assimilated by the economy (see Bartel and Lichtenberg, 1994, for empirical evidence). Therefore, the IT revolution should be accompanied by a rise in the skill premium at least in the short run.

In our stationarized dynamic model, the skill premium is directly measured by the variable $\hat{w}_{t}=w_{t} / b_{t}$. Figure 5.1 displays the dynamics of the skill premium when the adverse shock only occurs at $t=1$. From sub-section 4.1 , we know that the demand for skilled workers in the research sector will increase, which tends to push up the skill premium at $t=1$. Things are not that simple in our model since unskilled workers are also involved in the IT revolution: It is the labor force used for producing softwares. However, when the adverse shock is transitory, the consumption smoothing mechanism leads to delay the production of softwares by one period. Hence, the skill premium should unambiguously rise at $t=1$, and that is what Figure 5.1 says. Things are certainly less clear when the adverse shock is permanent since the consumption smoothing mechanism is no longer at work. As seen before, in such a case the demand for unskilled workers in the intermediate good sector rises at $t=1$, which tends to push upward the wage rate of these workers. Figure 5.2 reports the results of the permanent shock simulation. Though the demand for unskilled workers does rise in the intermediate good sector, the induced pressure on these workers' wage is not enough to offset the skill premium at $t=1$. In our experiments, skilled workers turn out to be "more needed" than the unskilled to launch and implement the IT revolution, and this is reflected in a skill premium which prevails in the short run independently of the timing of the adverse shocks.

The specifications adopted as for the type of labor input required in each sector are obviously crucial in the results stated above. In particular, since our IT sectors also employ unskilled workers in pure production tasks, which seems to us highly reasonable, 


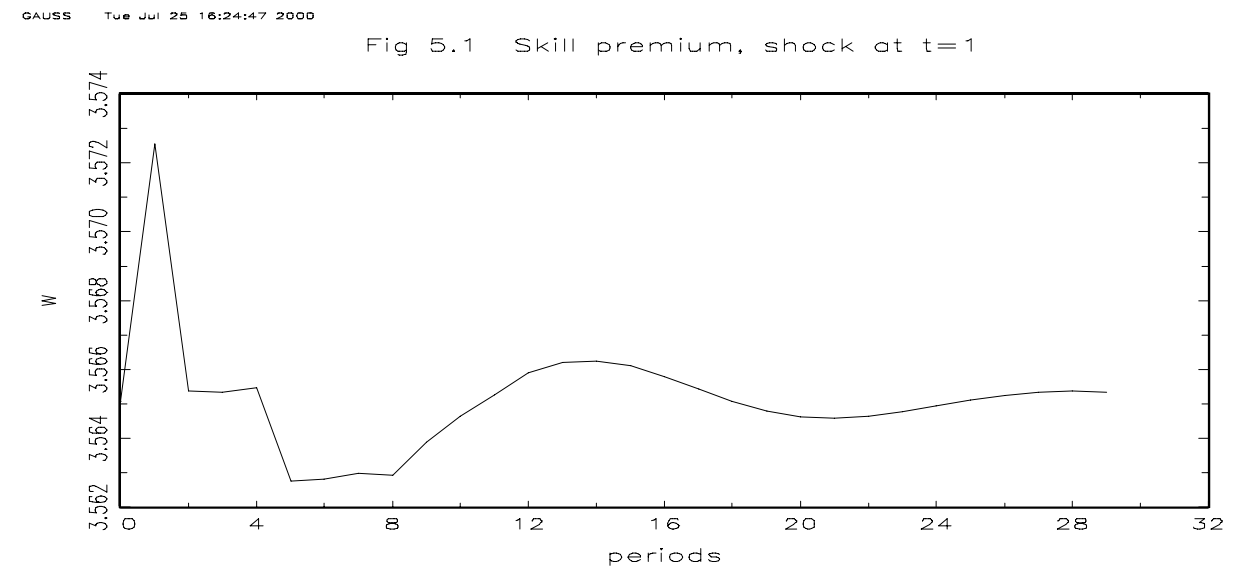

GAUSS Tue Jul 25 15:44:07 2000

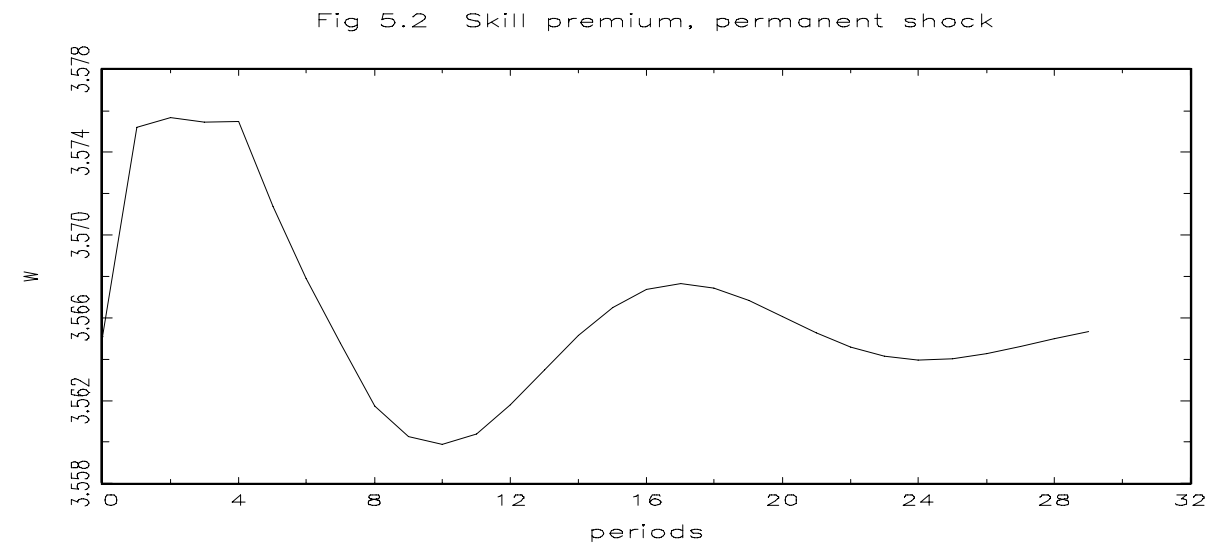



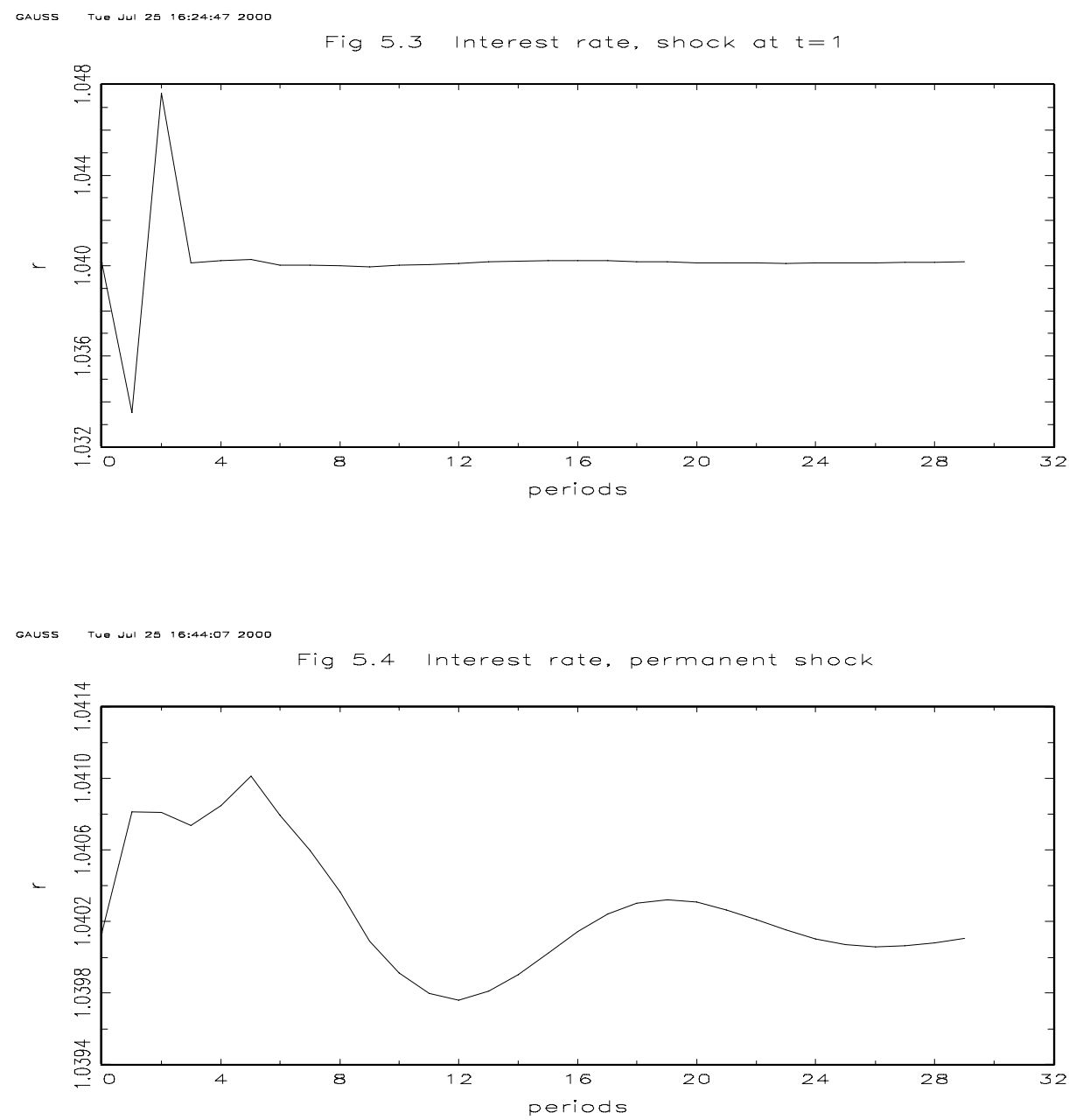

things are not that clear. Undeniably if adoption costs are included in our model as in Greenwood and Yorukoglu (1997), the story would be more complete: Skilled labor is not only needed to create new softwares, it is also needed to adopt the innovations. Though skilled people are employed in the final goods sector in our model, there is no explicit adoption task which entirely lies on the shoulders of the latter. Our approach is indeed complementary to the story told by Greenwood and Yorukoglu: While skilled labor is required for technology adoption, unskilled people are also needed in the production of the intermediate goods associated with the innovations.

The skill premium debate is part of a larger debate on the income distribution effects of the IT revolution. Another fundamental point concerns the consequences on the stock market evolution in line with the discussion opened by Greenwood and Jovanovic (1999) and even more recently by Jovanovic and Rousseau (2000). We could have much more comprehensively studied this question by introducing a stock market and an explicit decision on the distribution of dividends as did Greenwood and Yorukoglu in their 1997 paper. Our model is too simple on the financial markets side to bring out interesting lessons regarding these issues. The linear technologies adopted for the intermediate and research sector do not help much in this respect. As an example, 
one can check that the ratio "value of the firms in the research sector" to "skilled labor wage", namely $\frac{v_{t}}{w_{+}}$, is exactly equal at equilibrium to the skilled labor assigned to the research sector. We know from subsection 4.1 that the latter sharply increases in the short run when the economy is affected by adverse shocks, which in turn means that the value of the firms creating softwares will sharply increase in the short run too. Though this result is good in itself, it is too mechanically generated to be taken more seriously than an elementary consequence of our simple technological specifications of the IT sectors.

To end this income consequences subsection, let us have a quick look at the dynamics of the interest rate in our model. Figures 5.3 and 5.4 give the solution paths for the interest rate when the economy is respectively affected by an adverse shock at $t=1$ and by a permanent adverse shock. When the shock is permanent, the interest rate increases slightly at $t=1$, while it markedly goes down from $4 \%$ to nearly $3 \%$ at $t=1$ when the shock only hits the economy during this period. We can interpret these results using the same type of arguments as those in the previous subsection on labor productivity slowdown. Indeed, as usual, an adverse shock on $z_{t}$ has basically two effects on the interest rate: a negative one through the diminished marginal product of capital, and a positive one through the decrease in the level of production of the economy inducing excess demand and diminishing desired real saving. When the shock is transitory, the magnitude of the temporary IT revolution is not big enough to offset the negative consequences of the adverse shock on the marginal productivity of capital. Indeed, the latter also dominates the positive effect described above, and the interest rate goes down at $t=1$. In contrast, when the shock is permanent, the magnitude of the IT revolution is sufficiently big to counter-balance the negative consequences of the adverse shock on the marginal productivity of capital: The rising rate of embodied technological progress markedly improves the return to capital, an so should rise the interest rate. Our exercise thus clearly points at an IT pressure on the interest rate if the associated rate of embodied progress is enough important and persistent.

\section{Conclusion}

This work has been essentially conducted to theoretically study the conditions under which an IT revolution may endogenously occur. In contrast to previous contributions (among them the seminal paper of Greenwood, Hercowitz and Krusell, 1997), we don't assume that there has been an exogenous acceleration in the rate of embodied technological change; rather we try to identify the mechanisms leading to an endogenous IT boom. To this end, we have considered an economy with a preeminent IT sector. In modeling this sector, we meet some fundamental characteristics. First at all, technological progress is embodied. The new softwares can only be run on the the most recent generations of hardware for technical compatibility requirements. So we construct a vintage capital model à la Solow (1960) which additionally gives rise to endogenous growth. Indeed, we introduce a separate research sector (producing softwares) with a market power (copyrights) accruing to the innovator so as to stimulate innovation and growth. Finally, while the new softwares are copyrighted during a fixed period of time, they become public knowledge at a certain point in time, which generates positive externalities in the rest of the economy: The information technology may a be a 
powerful engine of growth.

Due to strategic complementarities of the same type as those pointed out by Boucekkine, del Río and Licandro (2000), our model can give rise to multiple steady states. We have given some insight into this issue together with some theoretical outcomes on the long run equilibrium. Then we focus on the dynamic response of the economy to adverse shocks on the level of disembodied technological progress. The latter shocks are considered to mimic say the oil shocks. We derive different interesting results. First, an adverse shock on the level of disembodied technological progress is shown to give rise to substitution effects: The labor resources of the economy are generally diverted from the final goods sector to sustain the creation and production of new softwares. During the IT boom, labor productivity's growth slowdowns, the skill premium rises as well as the value of firms undertaking research. In this respect, our model performs very well. However, as the considered shock, even permanent, does not affect the long run growth, the registered IT boom is always transitory and nothing can be said about the long run sustainability of an IT-driven growth regime. This should the next step in our research schedule. 


\section{References}

Bartel, A. and F. Lichtenberg (1987), "The Comparative Advantage of Educated Workers in Implementing New Technology", Review of Economics and Statistics 69, 1-11.

Blanchard, O. and C. Kahn (1980), "The Solution of Linear Difference Models under Rational expectations", Econometrica 48, 1305-1311.

Boucekkine, R., F. del Río and O. Licandro (2000), “A Schumpeterian Vintage Capital Model: An Attempt at Synthesis", Discussion Paper, IRES-Université catholique de Louvain.

Boucekkine, R. (1995), “An Alternative Methodology for Solving Nonlinear ForwardLooking Models", Journal of Economic Dynamics and Control 19, 711-734.

Cooper, R., and A. John (1988), "Coordinating Coordination Failures in Keynesian Models", Quarterly Journal of Economics 103, 441-463.

del Río, F. (1999), Competencia Monopolística en Modelos de Generaciones Solapadas y Progreso Técnico Incorporado en Modelos de Generaciones de Capital, Unpublished PhD thesis, Universidad Carlos III de Madrid.

Gordon, R. (2000), "Does the "New Economy" Measure up to the Great Inventions of the Past?", Journal of Economic Perspectives, forthcoming.

Gordon, R. (1999), "Has the "New Economy" Rendered the Productivity Slowdown Obsolete?", Mimeo, Northwestern University.

Gordon, R. (1990), The Measurement of Durable Goods Prices, University of Chicago Press.

Greenwood, J. and B. Jovanovic (1999), "The IT Revolution and the Stock Market", American Economic Review Papers and Proceedings 89.

Greenwood, J. and B. Jovanovic (1998), "Accounting for Growth", NBER Working Paper 6647.

Greenwood, J., Z. Hercowitz and P. Krusell (1997), “Long-Run Implications of InvestmentSpecific Technological Change", American Economic Review 87, 342-362.

Greenwood, J., and M. Yorukoglu (1997), "1974" Carnegie-Rochester Conference Series on Public Policy 46, 49-95.

Griliches, Z. (1994), "Productivity, RD, and the Data Constraint", American Economic Review 84, 1-23.

Griliches, Z. (1969), "Capital Skill Complementarity”, Review of Economics and Statistics $51,465-468$.

Grossman, G., and E. Helpman (1991), Innovation and Growth in the Global Economy, MIT Press.

Howitt, P., and P. Aghion (1998), "Capital Accumulation and Innovation as Complementary Factors in Long-Run Growth", Journal of Economic Growth 3, 111-130. 
Hsieh, C-T. (2000), "Endogenous Growth and Obsolescence", Mimeo, Department of Economics, Princeton University. Forthcoming in Journal of Development Economics.

Hulten, C. (1992), "Growth Accounting when Technical Change is Embodied in Capital", American Economic Review 82, 964-980.

Jorgenson, D. and K. Stiroh (2000), "Raising the Speed Limit: Us Economic Growth in the Information Age", Journal of Economic Perspectives, forthcoming.

Jorgenson, D. and K. Stiroh (1999), "Information Technology and Growth", American Economic Review Papers and Proceedings 89, 109-115.

Jovanovic, B. and P. Rousseau (2000), "Accounting for Stock Market Growth: 18851998", Mimeo, New York University.

Judd, K. (1985), “On the Performance of Patents”, Econometrica 53, 567-585.

Juillard, M. (1996), “DYNARE, a Program for the Resolution of Nonlinear Models with Forward-Looking Variables. Release 2.1", CEPREMAP.

Krusell, P. (1998), "Investment-Specific R\&D and the Decline in the Relative Price of Capital", Journal of Economic Growth 3, 131-141.

Michel, Ph. and J. Nyssen (1998), "On Knowledge Diffusion, Patents Lifetime and Innovation Based Endogenous Growth", Annales d'Economie et de Statistique 49-50, 77-103.

Oliner, S. and D. Sichel (2000), "The Resurgence of Growth in the Late 1990's: Is Information Technology the Story?", Journal of Economic Perspectives, forthcoming.

Romer, P. (1987), "Growth Based on Increasing Returns Due to Specialization", American Economic Review Papers and Proceedings 77, 56-72.

Solow, R. (1960), "Investment and Technological Progress" in Kenneth J. Arrow, Samuel Karlin and Patrick Suppes, Eds., Mathematical Methods in the Social Sciences 1959, Stanford University Press, 89-104.

Whelan, K. (2000), "Computers, Obsolescence, and Productivity", Mimeo, Federal Reserve Board, Division of Research and Statistics.

Young, A. (1993), "Substitution and Complementarity in Endogenous Innovation", Quarterly Journal of Economics 108, 775-807. 


\section{A The equilibrium}

The demand of unskilled labor from the intermediate goods sector is obtained using equations (21), (19), (22) and (23):

$$
\begin{aligned}
\int_{0}^{n_{t}} \tilde{L}_{i, t} \mathrm{~d} i & =\int_{0}^{n_{t}^{c}}\left(\frac{I_{t}}{b_{t}}\right)^{\sigma} q_{t}^{1-\sigma} \mathrm{d} i+\left(1-\frac{1}{\sigma}\right)^{\sigma} \int_{n_{t}^{c}}^{n_{t}}\left(\frac{\tau I_{t}}{b_{t}}\right)^{\sigma} q_{t}^{1-\sigma} \mathrm{d} i \\
& =\left(n_{t}^{c}+\left(1-\frac{1}{\sigma}\right)^{\sigma}\left(n_{t}-n_{t}^{c}\right)\right)\left(\frac{I_{t}}{b_{t}}\right)^{\sigma} q_{t}^{1-\sigma}
\end{aligned}
$$

Using this result and equations (15) and (31), the equilibrium on the unskilled labor market can be rewritten

$$
L=\left(\frac{\beta^{\beta} \alpha^{1-\beta} z_{t}}{b_{t}^{1-\beta} w_{t}^{\beta}}\right)^{\frac{1}{\gamma}} K_{t}+\left(n_{t}^{c}+\left(1-\frac{1}{\sigma}\right)^{\sigma}\left(n_{t}-n_{t}^{c}\right)\right)\left(\frac{\tau I_{t}}{b_{t}}\right)^{\sigma} q_{t}^{1-\sigma}
$$

which is equation (33) of the main text.

From equations (16), (30), and (28) we have

$$
H=\left(\frac{\alpha^{\alpha} \beta^{1-\alpha} z_{t}}{b_{t}^{\alpha} w_{t}^{1-\alpha}}\right)^{\frac{1}{\gamma}} K_{t}+\frac{\Delta n_{t}}{a m_{t}}
$$

which is equation (34) of the main text.

The equilibrium on the final good market, using (15), (16), (32), (18), is

$$
z_{t}^{\frac{1}{\gamma}} K_{t}\left(\frac{\alpha}{b_{t}}\right)^{\frac{\alpha}{\gamma}}\left(\frac{\beta}{w_{t}}\right)^{\frac{\beta}{\gamma}}=C_{t}+I_{t}
$$

which is equation (35) of the main text.

Solving (13) for $L_{t, s}$ and (14) for $H_{t, s}$,

$$
\begin{aligned}
& \left(\frac{\beta^{\beta} \alpha^{1-\beta} z_{s}}{b_{s}^{1-\beta} w_{s}^{\beta}}\right)^{\frac{\alpha}{\gamma}}\left(q_{t} E_{t, s}\right)^{\alpha}=L_{t, s}^{\alpha} \\
& \left(\frac{\alpha^{\alpha} \beta^{1-\alpha} z_{s}}{w_{s}^{1-\alpha} b_{s}^{\alpha}}\right)^{\frac{\beta}{\gamma}}\left(q_{t} E_{t, s}\right)^{\beta}=H_{t, s}^{\beta}
\end{aligned}
$$

replacing them in (6), using the definition of $E_{t, s}$ given in (1), and simplifying yields

$$
\gamma q_{t} \sum_{s=t}^{\infty} R_{t}^{s} z_{s}^{\frac{1}{\gamma}}(1-\delta)^{s-t}\left(\frac{\alpha}{b_{s}}\right)^{\frac{\alpha}{\gamma}}\left(\frac{\beta}{w_{s}}\right)^{\frac{\beta}{\gamma}} \mathrm{d} s=1
$$

Which gives the following law of motion for $q_{t}$ :

$$
\gamma q_{t} z_{t}^{\frac{1}{\gamma}}\left(\frac{\alpha}{b_{t}}\right)^{\frac{\alpha}{\gamma}}\left(\frac{\beta}{w_{t}}\right)^{\frac{\beta}{\gamma}}=1-\frac{(1-\delta) q_{t}}{\left(1+r_{t+1}\right) q_{t+1}}
$$

which establishes that the marginal productivity of capital should equal its user cost and is equation (36) of the main text. 
Consumption dynamics is given by (29) yielding equation (37) of the main text. Capital accumulation is given by (11) which is equation (38) of the main text.

$q_{t}$ can be determined using equations (3), (19), (22) and (23):

$$
\left(\frac{b_{t} q_{t}}{\tau I_{t}}\right)^{\sigma}=\left(n_{t}^{c}+\left(n_{t}-n_{t}^{c}\right)\left(1-\frac{1}{\sigma}\right)^{\sigma-1}\right)^{\frac{\sigma}{\sigma-1}}
$$

which is equation (39) of the main text.

Finally, using (26) and (27), the free entry condition becomes:

$$
\frac{w_{t}}{a m_{t}}=\frac{1}{\sigma-1}\left(1-\frac{1}{\sigma}\right)^{\sigma} \sum_{z=t}^{t+T} R_{t}^{z}\left(\frac{b_{z}}{\tau}\right)^{1-\sigma} I_{z}^{\sigma} q_{z}^{1-\sigma}
$$

which yields:

$$
\tau^{1-\sigma} \frac{\sigma-1}{a}\left(\frac{w_{t}}{m_{t}}-\frac{R_{t}^{t+1} w_{t+1}}{m_{t+1}}\right)=\left(1-\frac{1}{\sigma}\right)^{\sigma}\left(b_{t}^{1-\sigma} q_{t}^{1-\sigma} I_{t}^{\sigma}-R_{t}^{t+T+1} b_{t+T+1}^{1-\sigma} q_{t+T+1}^{1-\sigma} I_{t+T+1}^{\sigma}\right)
$$

which is equation (40) of the main text.

Finally, (41) is obtained from (24).

\section{B The stationarized dynamic system}

The dynamic system (33)-(41) can be rewritten as

$$
\begin{aligned}
& \left(\frac{\beta^{\beta} \alpha^{1-\beta} z_{t}}{\hat{w}_{t}^{\beta}}\right)^{\frac{1}{\gamma}} \hat{K}_{t} \hat{n}_{t}^{\frac{1}{(\sigma-1)(1-\gamma)}}+\left(d_{t}+\left(1-\frac{1}{\sigma}\right)^{\sigma}\left(1-d_{t}\right)\right)\left(\tau \hat{I}_{t}\right)^{\sigma} \hat{q}_{t}^{1-\sigma} \hat{n}_{t}=L \\
& \left(\frac{\alpha^{\alpha} \beta^{1-\alpha} z_{t}}{\hat{w}_{t}^{1-\alpha}}\right)^{\frac{1}{\gamma}} \hat{K}_{t} \hat{n}_{t}^{\frac{1}{(\sigma-1)(1-\gamma)}}+\frac{g_{t}-1}{a g_{t} \hat{m}_{t}}=H \\
& z_{t}^{\frac{1}{\gamma}} \hat{K}_{t} \hat{n}_{t}^{\frac{1}{(\sigma-1)(1-\gamma)}} \alpha^{\frac{\alpha}{\gamma}}\left(\frac{\beta}{\hat{w}_{t}}\right)^{\frac{\beta}{\gamma}}=\hat{C}_{t}+\hat{I}_{t} \\
& \gamma \hat{q}_{t} z_{t}^{\frac{1}{\gamma}} \alpha^{\frac{\alpha}{\gamma}}\left(\frac{\beta}{\hat{w}_{t}}\right)^{\frac{\beta}{\gamma}}+\frac{1-\delta}{1+r_{t+1}} g_{t+1}^{\frac{-1}{\sigma-1}}\left(\frac{\hat{n}_{t}}{\hat{n}_{t+1}}\right)^{\frac{-1}{\sigma-1}} \frac{\hat{q}_{t}}{\hat{q}_{t+1}}=1 \\
& g_{t+1}^{\frac{\gamma}{(1-\gamma)(\sigma-1)}} \frac{\hat{C}_{t+1}}{\hat{C}_{t}}\left(\frac{\hat{n}_{t}}{\hat{n}_{t+1}}\right)^{\frac{\gamma}{(1-\gamma)(\sigma-1)}}=\left(1+r_{t+1}\right) \rho \\
& \hat{K}_{t}-(1-\delta) \hat{K}_{t-1} g_{t}^{\frac{-1}{(\sigma-1)(1-\gamma)}}=\hat{q}_{t} \hat{I}_{t} \hat{n}_{t}^{\frac{-1}{(1-\gamma)(\sigma-1)}} \\
& d_{t}+\left(1-d_{t}\right)\left(1-\frac{1}{\sigma}\right)^{\sigma-1}=\left(\frac{\hat{q}_{t}}{\hat{\tau} I_{t}}\right)^{\sigma-1} \frac{1}{\hat{n}_{t}} \\
& \frac{\tau^{1-\sigma}(\sigma-1)^{1-\sigma} \sigma^{\sigma}}{a}\left(\frac{\hat{w}_{t}}{\hat{m}_{t}}-\frac{\hat{w}_{t+1} g_{t+1}^{\frac{\gamma}{(1-\gamma)(\sigma-1)}-1}\left(\frac{\hat{n}_{t}}{\hat{n}_{t+1}}\right)^{\frac{\gamma}{(1-\gamma)(\sigma-1)}}}{\left(1+r_{t+1}\right) \hat{m}_{t+1}}\right)+
\end{aligned}
$$




$$
\begin{gathered}
\left(\prod_{i=1}^{T} \frac{1}{1+r_{t+i}}\right) \hat{I}_{t+T}^{\sigma} \hat{q}_{t+T}^{1-\sigma} \hat{n}_{t+T}\left(\prod_{i=0}^{T-1} g_{t+i+1}^{\frac{\gamma}{(1-\gamma)(\sigma-1)}-1}\left(\frac{\hat{n}_{t+i}}{\hat{n}_{t+1+i}}\right)^{\frac{\gamma}{(1-\gamma)(\sigma-1)}}\right)=\hat{I}_{t}^{\sigma} \hat{q}_{t}^{1-\sigma} \hat{n}_{t} \\
\hat{m}_{t}=\theta+(1-\theta) \prod_{i=0}^{T-1} \frac{1}{g_{t}}
\end{gathered}
$$

with

$$
d_{t}=\prod_{i=0}^{T-1} \frac{1}{g_{t-i}}
$$

\section{The stationarized long run system}

Let us denote by (SL) the steady state system as formulated in Proposition 3. We write $\hat{x}=x$ for any variable $x$ to unburden the notations in this appendix. Using the fifth equation of (SL), we get directly

$$
r=\Psi_{r}(g)=\frac{g^{\frac{\gamma}{\alpha_{1}}}}{\rho}-1 .
$$

Using the last equation of (SL), we can derive the following important relation

$$
w=\Psi_{1}(g) I^{\sigma} q^{1-\sigma} n,
$$

with $\Psi_{1}(g)$ given by the following expression provided $\Psi_{r}(g)$ :

$$
\Psi_{1}(g)=\frac{1-\left(\frac{\rho}{g}\right)^{T}}{A^{1}\left(1-\frac{\rho}{g}\right)}\left((1-\theta) g^{-T}+\theta\right),
$$

with $A^{1}=\tau^{1-\sigma} \frac{(\sigma-1)^{1-\sigma} \sigma^{\sigma}}{a}$. On the other hand, the second equation of (SL) yields

$$
K n^{\frac{1}{\alpha_{1}}}=\Psi_{2}(g) w^{\frac{1-\alpha}{\gamma}},
$$

with

$$
\Psi_{2}(g)=\frac{H-\frac{g-1}{a g\left((1-\theta) g^{-T}+\theta\right)}}{A^{2} z^{\frac{1}{\gamma}}},
$$

where $A^{2}=\left(\alpha^{\alpha} \beta^{1-\alpha}\right)^{\frac{1}{\gamma}}$. Putting (54) and (55) into the first equation of (SL) we get the intended functional relation $w=\Psi_{w}(g)$ with

$$
\Psi_{w}(g)=\frac{\beta L}{\alpha\left(H-\frac{g-1}{a g\left((1-\theta) g^{-T}+\theta\right)}\right)+\tau^{\sigma} \frac{g^{-T}+\left(1-\frac{1}{\sigma}\right)^{\sigma}\left(1-g^{-T}\right)}{\Psi_{1}(g)}} .
$$

Now using the seventh equation of (SL) and provided (54), we can derive immediately a gfunction for $I$ given $\Psi_{w}(g)$ :

$$
I=\Psi_{I}(g)=\frac{\Psi_{w}(g)}{\Psi_{1}(g)}\left(g^{-T}+\left(1-\frac{1}{\sigma}\right)^{\sigma-1}\left(1-g^{-T}\right)\right) \tau^{\sigma-1} .
$$


The g-functional expression for $C$ is then computed from the third equation of (SL) and using additionally the relation (55):

$$
C=\Psi_{C}(g)=\frac{1}{\beta}\left(H-\frac{g-1}{a g\left((1-\theta) g^{-T}+\theta\right)}\right) \Psi_{w}(g)-\Psi_{I}(g) .
$$

Note that the g-functional expressions derived so far are independent of the value of $z$ as stated in Proposition 5. According to the same proposition, $z$ should be a determinant of the stationarized variables $q, n$ and $K$. This is indeed obvious to check. Immediately from the fourth equation of (SL), on can derive that:

$$
q=\Psi_{q}(g)=\left(1-\rho(1-\delta) g^{\frac{1}{\alpha_{1}}}\right) \frac{\left(\Psi_{w}(g)\right)^{\frac{\beta}{\gamma}}}{\gamma A^{3} z^{\frac{1}{\gamma}}},
$$

with $A^{3}=\left(\alpha^{\alpha} \beta^{\beta}\right)^{\frac{1}{\gamma}}$. A decrease in $z$ increases the value of the stationarized $q$, or in other terms it rises the value of embodied technological progress with respect to a measure of the raw labor cost by definition of the stationarized $q$. One can check that $z$ has the same effect on the stationarized $n$ and the opposite effect on the stationarized $K$. Indeed, the g-functional expressions of the two latter variables can be trivially from the already computed g-functions. after some trivial algebraic work:

$$
\begin{gathered}
n=\Psi_{n}(g)=\left(\frac{\Psi_{w}(g)}{\Psi_{1}(g)}\right)\left(\Psi_{I}(g)\right)^{-\sigma}\left(\Psi_{q}(g)\right)^{\sigma-1}, \\
K=\Psi_{K}(g)=\Psi_{2}(g)\left(\Psi_{w}(g)\right)^{\frac{1-\alpha}{\gamma}}\left(\Psi_{n}(g)\right)^{\frac{-1}{\alpha}} .
\end{gathered}
$$

